\title{
The analysis of large-scale turbulence characteristics in the Indonesian seas derived from a regional model based on the Princeton Ocean Model
}

\author{
K. O’Driscoll ${ }^{1, *}$ and V. Kamenkovich ${ }^{2}$ \\ ${ }^{1}$ Institute of Oceanography, Centre for Marine and Atmospheric Sciences, University of Hamburg, Bundesstrasse 53, \\ 20146 Hamburg, Germany \\ ${ }^{2}$ Department of Marine Science, The University of Southern Mississippi, Stennis Space Center, MS 39529, USA \\ *now at: Environmental Engineering Research Centre, School of Planning, Architecture \& Civil Engineering, \\ Queen's University Belfast, UK
}

Correspondence to: K. O’Driscoll (kieran.odriscoll@qub.ac.uk)

Received: 6 December 2011 - Published in Ocean Sci. Discuss.: 16 January 2012

Revised: 13 July 2012 - Accepted: 16 July 2012 - Published: 15 August 2012

\begin{abstract}
Turbulence characteristics in the Indonesian seas on the horizontal scale of order of $100 \mathrm{~km}$ were calculated with a regional model of the Indonesian seas circulation in the area based on the Princeton Ocean Model (POM). As is well known, the POM incorporates the Mellor-Yamada turbulence closure scheme. The calculated characteristics are: twice the turbulence kinetic energy per unit mass, $q^{2}$; the turbulence master scale, $\ell$; mixing coefficients of momentum, $K_{\mathrm{M}}$; and temperature and salinity, $K_{\mathrm{H}}$; etc. The analyzed turbulence has been generated essentially by the shear of large-scale ocean currents and by the large-scale wind turbulence. We focused on the analysis of turbulence around important topographic features, such as the Lifamatola Sill, the North Sangihe Ridge, the Dewakang Sill, and the North and South Halmahera Sea Sills. In general, the structure of turbulence characteristics in these regions turned out to be similar. For this reason, we have carried out a detailed analysis of the Lifamatola Sill region because dynamically this region is very important and some estimates of mixing coefficients in this area are available.

Briefly, the main results are as follows. The distribution of $q^{2}$ is quite adequately reproduced by the model. To the north of the Lifamatola Sill (in the Maluku Sea) and to the south of the Sill (in the Seram Sea), large values of $q^{2}$ occur in the deep layer extending several hundred meters above the bottom. The observed increase of $q^{2}$ near the very bottom is
\end{abstract}

probably due to the increase of velocity shear and the corresponding shear production of $q^{2}$ very close to the bottom. The turbulence master scale, $\ell$, was found to be constant in the main depth of the ocean, while $\ell$ rapidly decreases close to the bottom, as one would expect. However, in deep profiles away from the sill, the effect of topography results in the $\ell$ structure being unreasonably complicated as one moves towards the bottom. Values of 15 to $20 \times 10^{-4} \mathrm{~m}^{2} \mathrm{~s}^{-1}$ were obtained for $K_{\mathrm{M}}$ and $K_{\mathrm{H}}$ in deep water in the vicinity of the Lifamatola Sill. These estimates agree well with basin-scale averaged values of $13.3 \times 10^{-4} \mathrm{~m}^{2} \mathrm{~s}^{-1}$ found diagnostically for $K_{\mathrm{H}}$ in the deep Banda and Seram Seas (Gordon et al., 2003) and a value of $9.0 \times 10^{-4} \mathrm{~m}^{2} \mathrm{~s}^{-1}$ found diagnostically for $K_{\mathrm{H}}$ for the deep Banda Sea system (van Aken et al., 1988). The somewhat higher simulated values can be explained by the presence of steep topography around the sill.

\section{Introduction}

We investigate the distribution of turbulence characteristics with horizontal scale on the order of $100 \mathrm{~km}$ in the deep layers of the Indonesian seas, calculated with a regional model of the Indonesian seas circulation. The model is based on the Princeton Ocean Model (POM), incorporating the Mellor-Yamada turbulence closure scheme. The POM is 
widely used in modeling the ocean circulation in various regions of the World Ocean (see http://www.aos.princeton. edu/WWWPUBLIC/htdocs.pom/ for POM details). POM output provides both dynamical (depth-integrated and 3-D velocities, temperature, salinity, and sea surface height) and turbulence characteristics (kinetic energy and master scale of turbulence, mixing coefficients of momentum, temperature and salinity, etc.). As a rule, the analysis of POM results concerning the 3-D circulation has been restricted to the study of the distribution of dynamical characteristics, and in a few papers only features of turbulence characteristics have been intrinsically analyzed (see, e.g. Ezer, 2000; Oey et al., 1985; Cummins, 2000; Wijesekera et al., 2003; and Ezer and Mellor, 2004). We think that the study of such features is essential to understanding the dynamics of the ocean circulation as well.

We found a consistent distribution of turbulence characteristics on the scale of order of $100 \mathrm{~km}$ for the entire Indonesian seas region. However, the interaction of the large-scale turbulence with shear flow around basic topographic features in the area appears to be of primary interest. To illustrate this interaction, we first provide sections of distributions of twice the turbulence kinetic energy (per unit mass), $q^{2}$, which will be called in what follows simply turbulence kinetic energy, and the coefficient of vertical mixing of momentum, $K_{\mathrm{M}}$, through the North Sangihe Ridge, the Dewakang Sill, the sills surrounding the Halmahera Sea (specifically the north and south sills), and the Lifamatola Sill (see Fig. 1 for model domain and section locations). In general, the structure turbulence characteristics in these regions turned out to be similar. So we decided to focus our detailed analysis on the Lifamatola region, from the southern Maluku Sea (north of the sill) to the Seram Sea (south of the sill), because dynamically this region is very important and some estimates of mixing coefficients there are available.

The Lifamatola Sill is the deepest connection between the Pacific Ocean and the interior Indonesian seas, the Banda Sea and the Flores Sea, and is the main source of deep water to the Seram and Banda Seas (see, e.g. Gordon, 2005; van Aken et al., 1988, 2009; and O'Driscoll and Kamenkovich, 2009). The deep flow across the Lifamatola Sill is one of the major components of the Indonesian Throughflow (ITF), which is a key element of the World Ocean thermohaline circulation system or ocean conveyor belt (see, e.g. Gordon, 2005 for details).

To the best of our knowledge, there have been only a few direct measurements of turbulence characteristics in the Indonesian seas area. We can refer to the pioneering paper of Stommel and Fedorov (1967), who discovered microstructure in temperature and salinity profiles from STD recorders near Timor and Mindanao, and detailed microstructure measurements made by Alford et al. (1999) in the Banda Sea near $100 \mathrm{~m}$ depth over a 2 -week period. Unfortunately, these data refer to small-scale turbulence and cannot be used for the comparison with our calculations. So we can rely only on estimates of basin-scale coefficients of vertical mixing in the Banda and Seram Seas derived from diagnostic calculations by Gordon et al. (2003), van Aken et al. (1988), and van Aken et al. (1991) based on the 1-D temperature equation suggested by Munk (1966).

To avoid confusion, we would like to stress that this paper is not intended to analyze the internal structure of turbulence. In this paper, we analyze the characteristics of vertical turbulence provided by Mellor-Yamada's scheme of parameterization. It is well known that all turbulence characteristics are chaotically pulsated both spatially and temporally. What types of fluid motions are responsible for these pulsations? Horizontal mixing is parameterized by Smagorinsky's formula, which takes into account sub-grid scale eddies. The specifics of these eddies are not elaborated upon. This formula is widely used in atmospheric and ocean modeling and is considered to be very effective. We focus on the analysis of vertical turbulent mixing in deep layers of the ocean, including the bottom boundary layer. The analysis is based essentially on the consideration of the turbulence kinetic energy equation. From the standpoint of this equation, we consider turbulence that is essentially generated by the shear of largescale ocean currents and by the large-scale wind turbulence. So, our focus is on turbulence associated with basin-scale motions in the Indonesian seas. This is the main reason why we call the analyzed turbulence large-scale turbulence. The effect of shear is balanced by the work of buoyancy forces, dissipation of the energy, vertical and horizontal diffusion, and vertical and horizontal advection. The contribution of lee waves into the shaping of $q^{2}$ is not considered explicitly because they occur at a much smaller scales, order of $100 \mathrm{~m}$. The analysis of such motions usually requires a nonhydrostatic model, very detailed bottom topography and horizontal grid spacing on the order of $10 \mathrm{~m}$ (see, e.g. Xing and Davies, 2006, 2007). The effect of internal waves is recognized separately but parameterized in the POM very crudely by the introduction of background mixing. It is worth noting here that currently there are no general cirulation models (GCMs) that are able to simulate simultaneously large-scale features of the circulation and such motions as small-scale eddies, filaments coming off eddies, internal waves or lee waves. The study of such motions is extremely important from the standpoint of the internal structure of turbulence, but all known GCMs are using some kind of parameterization for such motions. This does not mean that characteristics of turbulence provided by GCMs are of no interest. For example, the simple Munk model based on the 1-D temperature equation is used by many researchers to obtain an estimate of basin-scale turbulence mixing.

We stress that mixing coefficients $K_{\mathrm{M}}$ (momentum) and $K_{\mathrm{H}}$ (temperature and salinity) were not specified a priori, but calculated within the POM. Because the large-scale currents and temperature and salinity distributions have been adequately described by our model, we argue that the estimate of mixing coefficients $K_{\mathrm{M}}$ and $K_{\mathrm{H}}$ is also reasonable. 


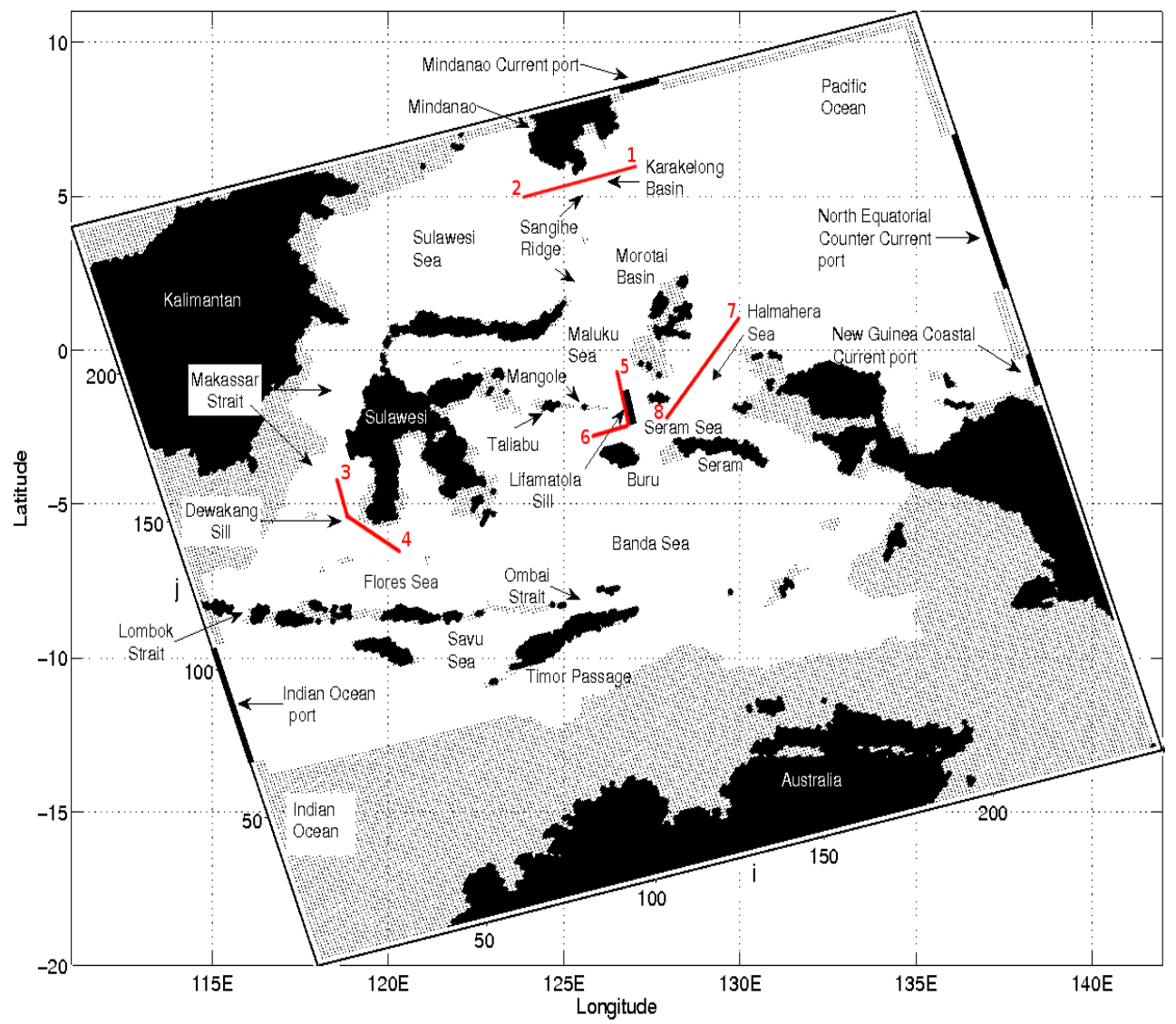

Fig. 1. The model domain location along with names of important topographic features and open ports. The model domain was rotated relative to lines of constant lat.-long. so that the Indian Ocean port was located on the JADE (Java-Australia Dynamics Experiment) August 1989 CTD (conductivity, temperature, depth) transect between northwestern Australia and Bali. The model $(x, y)$ domain ranges between $i$ and $j$ values of 1 to 250 (see $i, j$ values along model domain edge). Model domain corners in lat.-long. values are as follows: SW: $20^{\circ} \mathrm{S}$, $118^{\circ} \mathrm{E}$; SE: $13^{\circ} \mathrm{S}, 142^{\circ} \mathrm{E}$; NE: $11^{\circ} \mathrm{N}, 135^{\circ} \mathrm{E}$; and NW: $4^{\circ} \mathrm{N}, 111^{\circ} \mathrm{E}$. The 4 open ports are shown as bold lines along the edge of the model domain. The depth in the grey (dotted) region is less than $100 \mathrm{~m}$. However, the grey region in the Indian Ocean in the southwestern corner of the model domain is greater than $100 \mathrm{~m}$ but has been excluded from the model integration to facilitate the Indian Ocean open port. The red lines show locations of the sections through the North Sangihe Ridge (1-2), the Dewakang Sill (3-4), the Lifamatola Sill (5-6), and the Halmahera Sea (7-8), discussed in Sect. 3. The thick black line through the Lifamatola Sill in the north-south direction shows the location of the profiles discussed in Sect. 4.

Otherwise, we would not obtain an adequate description of currents and temperature and salinity distributions, because values of $K_{\mathrm{M}}$ and $K_{\mathrm{H}}$ directly impact those distributions. Ultimately, all indirect methods of estimating mixing coefficients are based on the assumption of the existence of close relationships between distributions of dynamical and mixing characteristics. Therefore, it is important to stress that all empirical constants in the Mellor-Yamada scheme are fixed and do not depend on the case considered. It is important to stress, also, that the validity of the Mellor-Yamada scheme has been successfully tested for a wide variety of engineering and geophysical flows (see Mellor and Yamada, 1982). It is worth noting here that the validity of our estimate of mixing coefficients was supported also by the comparison of them with coefficients estimated by Gordon et al. (2003) and van
Aken et al. (1988). The regional model of the Indonesian seas circulation allowed us to learn a lot about the distribution of dynamical characteristics (currents, temperature and salinity) in the region. We think that our estimates of large-scale turbulence characteristics are useful as well. Unfortunately, we have no directly measured data to support this statement. However, we also have no direct or indirect estimates against it. Our conclusion on the adequacy of estimated turbulence characteristics is based also on results of the analysis of their compatibility with some general principles.

We will start with a brief description of our model and basic equations for determining turbulence characteristics (Sect. 2). Then in Sect. 3 we discuss results of the analysis of turbulence characteristics around the basic topographic features mentioned above, and in Sect. 4 we discuss in detail 
$q$ and $\ell$ distributions and mixing coefficients $K_{\mathrm{M}}$ and $K_{\mathrm{H}}$ in the area of the Lifamatola Strait. Concluding remarks are outlined in Sect. 4.

\section{Model description}

For a full model description see O'Driscoll and Kamenkovich (2009). The model domain, Fig. 1, extends throughout the Indonesian seas region and has $250 \times 250$ grid cells in the horizontal, identified in Fig. 1 by $i$ and $j$. The model has horizontal resolution of $\sim 10 \mathrm{~km}$ in both $i$ and $j$-horizontal directions, which is sufficient to resolve all major topographic features in the region. The ETOPO5 data base was used in our calculation of smoothed topography. Important localized topographic features, such as sills, were smoothed following the recommendations of the POM, such that the basic structure of the sill was retained, while the bottom slope concerning the pressure gradient problem associated with the $\sigma$ coordinate system was not an issue. The model has four open ports to simulate the impact of major currents entering and exiting the region. The orthogonal curvilinear coordinate system used in the POM has been rotated relative to the latitude-longitude system so that the open port in the Indian Ocean region (IO port) lies on the transect line extending from Java to northwest Australia along which observations were made (see, e.g. Fieux et al., 1994; Sprintall et al., 2000). There are three open ports in the Pacific region: the Mindanao Current port in the north (MC port); the New Guinea Coastal Current port (NGCC port) just to the north of New Guinea/Irian Jaya; and the North Equatorial Counter Current port (NECC port) in the east (port locations are shown in Fig. 1). By and large, Pacific waters enter the model domain through the MC and NGCC ports and exit partially through the NECC port. Part of the Pacific waters enter the Indonesian seas area and cross through the region, before exiting the model domain in the Indian Ocean through the IO port. This is the Indonesian Throughflow (ITF). The grey (dotted) regions in Fig. 1 are shallow (depth is less than $100 \mathrm{~m}$ ) and are considered as land. However, the depth in the grey region in the Indian Ocean in the southwestern corner of the model domain is greater than $100 \mathrm{~m}$ but has been excluded from the model integration to facilitate the Indian Ocean open port. There are $29 \sigma$ levels in the vertical so that important features of the vertical structure of temperature and salinity are properly resolved over all types of topography.

At the open ports, normal depth-averaged velocities are specified based on the prescribed total transport and assumed simple distributions of this velocity across the port. For the normal velocity in 3-D motion, Orlanski's condition with nudging was employed (see Marchesiello et al., 2001). Tangential velocity is zero for both the 2-D and 3-D motion. POM recommended boundary conditions are used at closed boundaries. Because of various restrictions, e.g. the NGCC crossing the equator and the grid spacing of Levitus climatol- ogy (Conkright et al., 2002), it was not possible to calculate geostrophic velocities at the open ports from available observations and climatology. Therefore, as an alternative, we used published observations and some modeling results to determine typical port normal velocities and total port transports. A detailed analysis of observational data for all ports and calculation of port normal velocities and corresponding transports was performed. It was supposed that such an approach is more reliable than the use of results from a global ocean GCM.

At the sea surface boundary, the Adjusted Southampton Oceanography Centre (SOC) surface flux climatology (Grist and Josey, 2003) is used in the calculation of surface heat flux, which is equal to the sum of long wave radiation, latent heat (evaporation) and sensible heat fluxes. Since the flux of fresh water at the surface in the Indonesian seas is very poorly known, sea surface salinity is specified from Levitus climatology (Conkright et al., 2002). In the near surface and deep ocean (sub-thermocline water), a very weak nudging of $T$ and $S$ to climatology was introduced to account for mixing processes not correctly parameterized in the model. Monthly climatological winds are taken from the Comprehensive Ocean-Atmosphere Data Set (COADS), analyzed by da Silva et al. (1994) and are calculated at every internal time step.

Tides have not been directly included in the model. However, additional friction has been incorporated into the momentum equations as a proxy for important tidal friction in the vicinity of some passages and sills. The approach is rather crude but tides somehow needed to be taken into account. Otherwise, due to western intensification, for example, we obtained overly strong flows through certain passages and straits. A similar approach was taken by Schiller et al. (1998). The direct incorporation of tides is a separate difficult problem.

It is generally accepted now that a background diffusivity of $10^{-5} \mathrm{~m}^{2} \mathrm{~s}^{-1}$ is added to the coefficients of vertical mixing to represent mixing processes not modeled by the MellorYamada scheme (e.g. internal waves), see, e.g. Ezer (2000).

It was shown that the developed regional model adequately described the circulation in the Indonesian seas (O'Driscoll and Kamenkovich, 2009; Kamenkovich et al., 2009; Rosenfield et al., 2010). We list principal results here. First, we have shown that basic features of temperature and salinity distributions along with the current pattern with scale of order of $100 \mathrm{~km}$ were reproduced reasonably well. We demonstrated a satisfactory agreement of simulated transports with transports observed during the INSTANT program. Second, it was proved that the pressure difference between the $\mathrm{Pa}$ cific and Indian Ocean is not a major factor determining the total transport of the ITF. All factors influencing this total transport were revealed and their roles were clarified. Third, we managed to disclose the path of South Pacific Water entering the Indonesian seas region as a branch of the New Guinea Coastal Current. We have shown that this water flows 
around Halmahera island and then enters the region through the Maluku Sea and across the Lifamatola Strait.

The developed model uses the Mellor-Yamada scheme to describe turbulence characteristics. The scheme has been successsfully applied to various regions of the World Ocean. Although we did not find published results of direct comparison of turbulence characteristics simulated by the POM (incorporating the Mellor-Yamada scheme of closure) with corresponding observed characteristics, there are many results of modeling such phenomena, the structure of which depends significantly on the chosen scheme of closure. For example, Ezer (2005), studying results of modeling near the Denmark Straits bottom dense overflow, came to the conclusion that the "Mellor-Yamada scheme represents the subgrid-scale mixing very well." Similarly, Ezer and Weatherly (1990), studying pools of cold water flowing on the bottom of the ocean in the High Energy Benthic Boundary Layer Experiment region in the North Atlantic, concluded that bottom turbulence and boundary-layer dynamics were simulated adequately. The POM uses Smagorinsky's scheme to parameterize sub-grid scale horizontal diffusion of momentum and scalar characteristics.

For completeness of outline, we write out the basic relations of the Mellor-Yamada turbulence closure scheme (see Mellor, 2004). Coefficients of vertical mixing of momentum, $K_{\mathrm{M}}$, and vertical mixing of salt and temperature, $K_{\mathrm{H}}$, are represented by:

$K_{\mathrm{M}}=S_{\mathrm{M}} q \ell \quad K_{\mathrm{H}}=S_{\mathrm{H}} q \ell$.

We remind the reader that $q^{2}$ is twice the kinetic energy of turbulence (per unit mass), and $\ell$ is a master scale of turbulence. $S_{\mathrm{M}}$ and $S_{\mathrm{H}}$ are nondimensional characteristics depending on the Richardson number, $R i$ :

$R i=-\frac{\ell^{2}}{q^{2}} N^{2}$,

where $N$ is the local buoyancy frequency. For calculation of $S_{\mathrm{M}}$ and $S_{\mathrm{H}}$, the following empirical formulas are used:

$S_{\mathrm{H}}=\frac{A_{2}\left[1-6\left(A_{1} / B_{1}\right) \mathrm{stf}\right]}{1-\left[\left(3 A_{2} B_{2} / \mathrm{stf}\right)+18 A_{1} A_{2}\right] R i}$

and

$S_{\mathrm{M}}=\frac{A_{1}\left[1-3 C_{1}-6\left(A_{1} / B_{1}\right) \mathrm{stf}\right]+\left(18 A_{1}^{2}+9 A_{1} A_{2}\right) R i}{1-9 A_{1} A_{2} R i}$.

Here, "stf" is a function of $R i$. It is introduced to describe the effect of stratification;

$\operatorname{stf}(R i)= \begin{cases}1.0 & R i \geq 0 \\ 1.0-0.9\left(R i / R i_{\mathrm{c}}\right)^{3 / 2} & R i_{\mathrm{c}}<R i<0 \\ 0.1 & R i \leq R i_{\mathrm{c}} .\end{cases}$

Also, $\quad A_{1}=0.92, B_{1}=16.6, A_{2}=0.74, B_{2}=10.1, \quad$ and $C_{1}=0.08 . R i_{\mathrm{c}}$ is the critical value of $R i$, and $R i_{\mathrm{c}}=-6.0$.
Two equations are formulated to determine $q^{2}$ and $q^{2} \ell$ in $x, y$, and $\sigma$ coordinates; $\sigma=\frac{z-\eta}{H+\eta}$, where $H$ is the depth of the ocean and $\eta$ is sea surface height. The $q^{2}$ equation is:

$$
\begin{aligned}
& \frac{\partial q^{2} D}{\partial t}+\frac{\partial u q^{2} D}{\partial x}+\frac{\partial v q^{2} D}{\partial y}+\frac{\partial \omega q^{2}}{\partial \sigma} \\
& =\frac{\partial}{\partial \sigma} \frac{K_{q}}{D} \frac{\partial q^{2}}{\partial \sigma}+\frac{2 K_{\mathrm{M}}}{D}\left[\left(\frac{\partial u}{\partial \sigma}\right)^{2}+\left(\frac{\partial v}{\partial \sigma}\right)^{2}\right] \\
& -2 D K_{\mathrm{H}} N^{2}-\frac{2 D q^{3}}{B_{1} l} \mathrm{stf}+\frac{\partial}{\partial x}\left(H A_{\mathrm{H}} \frac{\partial q^{2}}{\partial x}\right) \\
& +\frac{\partial}{\partial y}\left(H A_{\mathrm{H}} \frac{\partial q^{2}}{\partial y}\right),
\end{aligned}
$$

where $u$ and $v$ are zonal and meridional velocities, respectively; $\omega$ is the "vertical" velocity in the POM (essentially, it is the difference between the particle velocity normal to the surface $\sigma=$ const, and the velocity with which the surface $\sigma=$ const is moving); $D=H+\eta ; K_{q}$ is the coefficient of vertical diffusion of $q^{2}$ where $K_{q}=0.41 K_{\mathrm{H}}$; and $A_{\mathrm{H}}=0.2 A_{\mathrm{M}}$, where $A_{\mathrm{M}}$ is the coefficient of horizontal diffusion of momentum, calculated from Smagorinsky's formula. The first term on the right-hand side (RHS) of Eq. (6) is the vertical diffusion; the second term is the production of turbulence kinetic energy (TKE) due to vertical shear; the third term is the work (per unit time) of buoyancy forces; the fourth term is the dissipation of TKE; and the fifth term is the horizontal diffusion of $q^{2}$.

It is useful to write out the difference form of Eq. (6). First, we integrate this equation over the grid cell with area $S_{g}$ and replace these integrals with $S_{g}$ multiplied by the integrand taken at the center of the cell. The superscript $n$ denotes the value of characteristic at time moment $t_{n}=n \Delta$, where $\Delta \mathrm{t}$ is the time step. Dividing all terms of the equation on $S_{g} D^{(n+1)}$ yields:

$\frac{\left(q^{2}\right)^{(n+1)}-\frac{D^{(n-1)}}{D^{(n+1)}}\left(q^{2}\right)^{(n-1)}}{2 \Delta \mathrm{t}}+$

$\frac{1}{D^{(n+1)} S_{g}}$ ([sum of horizontal advective fluxes

of $\left.\left.q^{2}-\mathrm{D}\right]+\frac{\partial \omega q^{2}}{\partial \sigma} S_{g}\right)^{(n)}=\frac{1}{\left(D^{(n+1)}\right)^{2}} \frac{\partial}{\partial \sigma}$

$\left[K_{q}^{(n)}\left(\frac{\partial q^{2}}{\partial \sigma}\right)^{(n+1)}\right]+\frac{2 K_{\mathrm{M}}^{(n)}}{\left(D^{(n+1)}\right)^{2}}\left[\left(\frac{\partial u}{\partial \sigma}\right)^{2}+\left(\frac{\partial v}{\partial \sigma}\right)^{2}\right]^{(n)}$ $-2 K_{\mathrm{H}}^{(n)} N^{2^{(n)}}-\frac{2 q^{(n-1)}}{B_{1} l^{(n-1)}} \operatorname{stf}^{(n)}\left(q^{2}\right)^{(n+1)}+$ $\frac{1}{D^{(n+1)} S_{g}}$ (sum of horizontal diffusion fluxes of $\left.q^{2}\right)^{(n-1)}$.

The $q^{2}$ equation is used in many turbulence closure schemes by invoking different parameterizations of 
diffusion, production and dissipation of turbulence energy. The $q^{2} \ell$ equation is utilized in the Mellor-Yamada scheme only (see a discussion in Burchard, 2001). This equation is as follows:

$$
\begin{aligned}
& \frac{\partial q^{2} \ell D}{\partial t} \frac{\partial u q^{2} \ell D}{\partial x}+\frac{\partial v q^{2} \ell D}{\partial y}+\frac{\partial \omega q^{2} \ell}{\partial \sigma} \\
& =\frac{\partial}{\partial \sigma} \frac{K_{q}}{D} \frac{\partial q^{2} \ell}{\partial \sigma}+E_{1} \ell \frac{K_{\mathrm{M}}}{D}\left[\left(\frac{\partial u}{\partial \sigma}\right)^{2}+\left(\frac{\partial v}{\partial \sigma}\right)^{2}\right] \\
& -E_{1}-\mathrm{D} \ell K_{\mathrm{H}} N^{2}-\frac{D q^{3}}{B_{1}} W \mathrm{stf}+\frac{\partial}{\partial x}\left(H A_{\mathrm{H}} \frac{\partial q^{2} \ell}{\partial x}\right) \\
& +\frac{\partial}{\partial y}\left(H A_{\mathrm{H}} \frac{\partial q^{2} \ell}{\partial y}\right)
\end{aligned}
$$

where $E_{1}=1.8, E_{2}=1.33$, and $W$ is the so-called wall proximity function,

$$
W=1+E_{2}\left[\frac{\ell}{\kappa}\left(|z-\eta|^{-1}+|z+H|^{-1}\right)\right]^{2},
$$

where $\kappa$ is von Karman's constant. The physical meaning of the separate terms on the RHS of Eq. (8) is the same as the corresponding terms of Eq. (6). The difference form of Eq. (8) is as follows:

$$
\frac{\left(q^{2} \ell\right)^{(n+1)}-\frac{D^{(n-1)}}{D^{(n+1)}}\left(q^{2} \ell\right)^{(n-1)}}{2 \Delta \mathrm{t}}+
$$

$\frac{1}{D^{(n+1)} S_{g}}([$ sum of horizontal advective

$$
\begin{aligned}
& \text { fluxes of } \left.\left.q^{2} \ell D\right]+\frac{\partial \omega q^{2} \ell}{\partial \sigma} S_{g}\right)^{(n)}= \\
& \frac{1}{\left(D^{(n+1)}\right)^{2}} \frac{\partial}{\partial \sigma}\left[K_{q}^{(n)}\left(\frac{\partial q^{2} \ell}{\partial \sigma}\right)^{(n+1)}\right]+E_{1} \ell^{(n)} \\
& \frac{K_{\mathrm{M}}^{(n)}}{\left(D^{(n+1)}\right)^{2}}\left[\left(\frac{\partial u}{\partial \sigma}\right)^{2}+\left(\frac{\partial v}{\partial \sigma}\right)^{2}\right]^{(n)}-
\end{aligned}
$$

$E_{1} \ell^{(n)} K_{\mathrm{H}}^{(n)} N^{2(n)}-\frac{q^{(n-1)}}{B_{1} \ell^{(n-1)}} W^{(n)} \mathrm{stf}^{(n)}\left(q^{2} \ell\right)^{(n+1)}+$

$\frac{1}{D^{(n+1)} S_{g}}$ (sum of horizontal diffusion

fluxes of $\left.q^{2} \ell\right)^{(n-1)}$.

The vertical boundary conditions for $q^{2}$ and $q^{2} \ell$ at the surface are, respectively,

$q^{2}=B_{1}^{2 / 3} \sqrt{\left(\frac{\tau_{x}}{\rho_{0}}\right)^{2}+\left(\frac{\tau_{y}}{\rho_{0}}\right)^{2}} ; \quad q^{2} \ell=0 \quad$ at $\quad z=0$

where $\tau_{x}$ and $\tau_{y}$ are the components of the wind stress, and $\rho_{0}$ is the mean density. The corresponding boundary condi- tions at the bottom are:

$q^{2}=B_{1}^{2 / 3} C_{z}^{2}\left(u^{2}+v^{2}\right) ; \quad q^{2} \ell=0 \quad$ at $\quad z=-H ;$

where $C_{z}$ is the so-called drag coefficient, calculated in the model by using the so-called law of the wall. The horizontal boundary conditions are:

$q^{2}=\varepsilon ; \quad q^{2} \ell=\varepsilon \quad$ at horizontal boundaries,

where $\varepsilon$ has been set to $10^{-10}$. The SI international system is used for dimensions of all variables considered.

\section{Analysis of turbulence characteristics around basic topographic features}

The results are taken from the 1 August during the South Eastern Monsoon (SEM) after $15 \mathrm{yr}$ of model integration.

By and large, very large values of turbulence kinetic energy, $q^{2}$, and coefficients of vertical mixing, $K_{\mathrm{M}}$ and $K_{\mathrm{H}}$, are found in deep water around topographic features such as sills, in the upper mixed layer and in the vicinity of strong currents in the thermocline. $q^{2}$ and mixing coefficients reduce to POM background values in the interior of the ocean away from topographic features. The turbulence kinetic energy, $q^{2}$, basically determines mixing coefficients, especially in the interior of the ocean, where the length scale $\ell$ is almost constant. Values of $q^{2}$ and mixing coefficients are greatest adjacent to the sills but patterns are complicated and perhaps noisy. Maximum values of $q^{2}$ are $\sim 10^{-3}-10^{-2} \mathrm{~m}^{2} \mathrm{~s}^{-2}$. Values are large, especially along sloping topography, and these large values can extend for significant distances in both upstream and downstream directions. In the interior of the ocean away from topographic features, $q^{2}$ is reduced to less than $10^{-8} \mathrm{~m}^{2} \mathrm{~s}^{-2}$. Maximum values of $K_{\mathrm{M}}$ and $K_{\mathrm{H}}$ are $\sim 10^{-1}-5 \times 10^{-1} \mathrm{~m}^{2} \mathrm{~s}^{-1}$ at the sills and along sloping topography, and can be as large as $\sim 5 \times 10^{-4} \mathrm{~m}^{2} \mathrm{~s}^{-1}$ for significant distances downstream and upstream of the sills. In the thermocline $q^{2}$ and coefficients of vertical turbulent mixing are generally small but increase noticeably where currents are known to be strong, with maximum values of $q^{2} \sim 5 \times 10^{-3} \mathrm{~m}^{2} \mathrm{~s}^{-2}$ and $K_{\mathrm{M}} \sim 10^{-2} \mathrm{~m}^{2} \mathrm{~s}^{-1}$. In the upper mixed layer (UML), large values of $q^{2}$ and coefficients of vertical turbulent mixing are generally confined to the upper $50 \mathrm{~m}$ with maximum values of $q^{2} \sim 10^{-3} \mathrm{~m}^{2} \mathrm{~s}^{-2}$ and $K_{\mathrm{M}}$ and $K_{\mathrm{H}} \sim 10^{-2} \mathrm{~m}^{2} \mathrm{~s}^{-1}$. The scale $\ell$ is generally small in the boundary layers, and large and almost constant in the interior (on the order of $100 \mathrm{~m}$ ).

Figure 1 shows the locations of sections presented for discussion. The results of estimation are shown in Figs. 2 to 5. We focus on 4 important passages through complex topography: the sill through the North Sangihe Ridge, the Dewakang Sill, the Lifamatola Sill, and the Halmahera Sea. Values of $q^{2}$ and $K_{\mathrm{M}}$ are given for each section. The full set of results, including $K_{\mathrm{H}}, \ell, S_{\mathrm{M}}$ and $S_{\mathrm{H}}$, have been given in O’Driscoll (2007). 

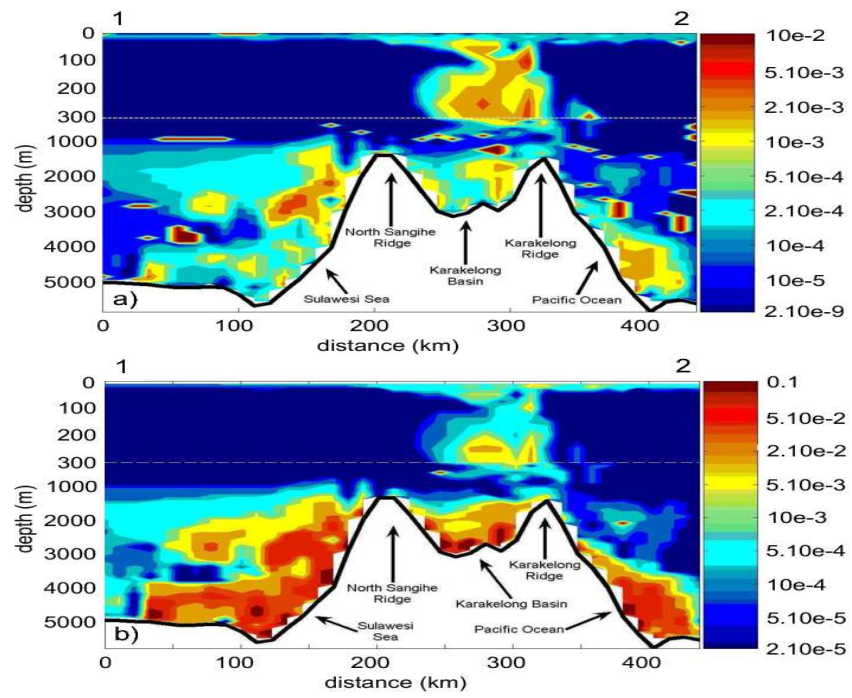

Fig. 2. Sections of (a) $q^{2}\left(\mathrm{~m}^{2} \mathrm{~s}^{-2}\right)$ and (b) $K_{\mathrm{M}}\left(\mathrm{m}^{2} \mathrm{~s}^{-1}\right)$ through the sill in the North Sangihe Ridge. Locations of points 1 and 2 at the top of the figures are given in Fig. 1.
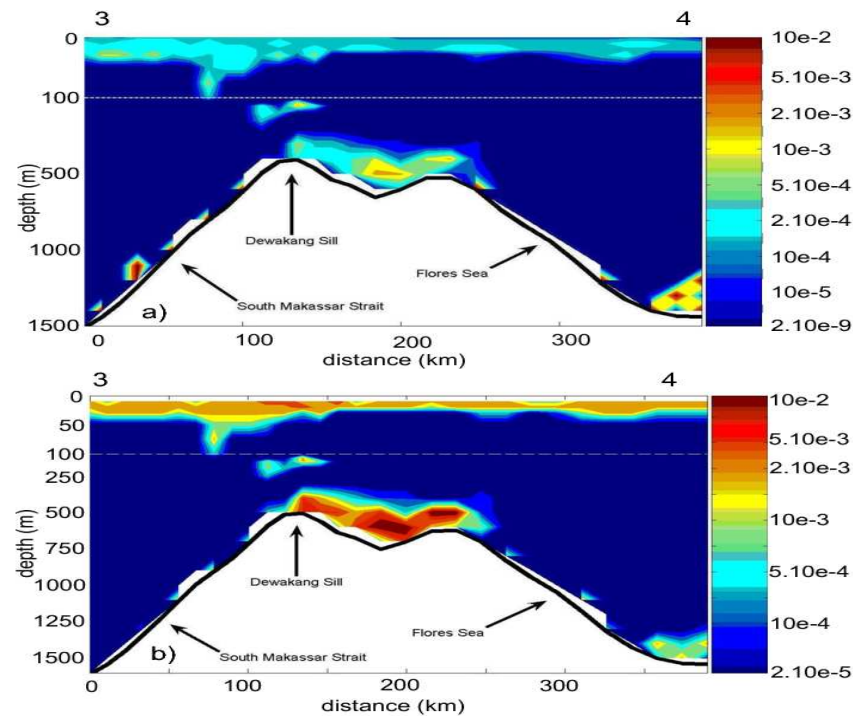

Fig. 3. Sections of (a) $q^{2}\left(\mathrm{~m}^{2} \mathrm{~s}^{-2}\right)$ and (b) $K_{\mathrm{M}}\left(\mathrm{m}^{2} \mathrm{~s}^{-1}\right)$ through the Dewakang Sill. Locations of points 3 and 4 at the top of the figures are given in Fig. 1.

Through the sill in the North Sangihe Ridge and downstream into the Sulawesi Sea, values of $q^{2}$ in the vicinity of bottom topography are $\sim 10^{-3} \mathrm{~m}^{2} \mathrm{~s}^{-2}$, or greater (Fig. 2a). The entire Karakelong Basin below the depth of the Sangihe Ridge, to the west, and the Karakelong Ridge, to the east, shows $q^{2}$ greater than $2 \times 10^{-4} \mathrm{~m}^{2} \mathrm{~s}^{-2}$. Moving away from topography, values of $q^{2}$ generally greater than $2 \times 10^{-4} \mathrm{~m}^{2} \mathrm{~s}^{-2}$ extend $150-200 \mathrm{~km}$ downstream of the North Sangihe Ridge and into the Sulawesi Basin. Upstream of the Karakelong Ridge in the Pacific Ocean, $q^{2}$ generally
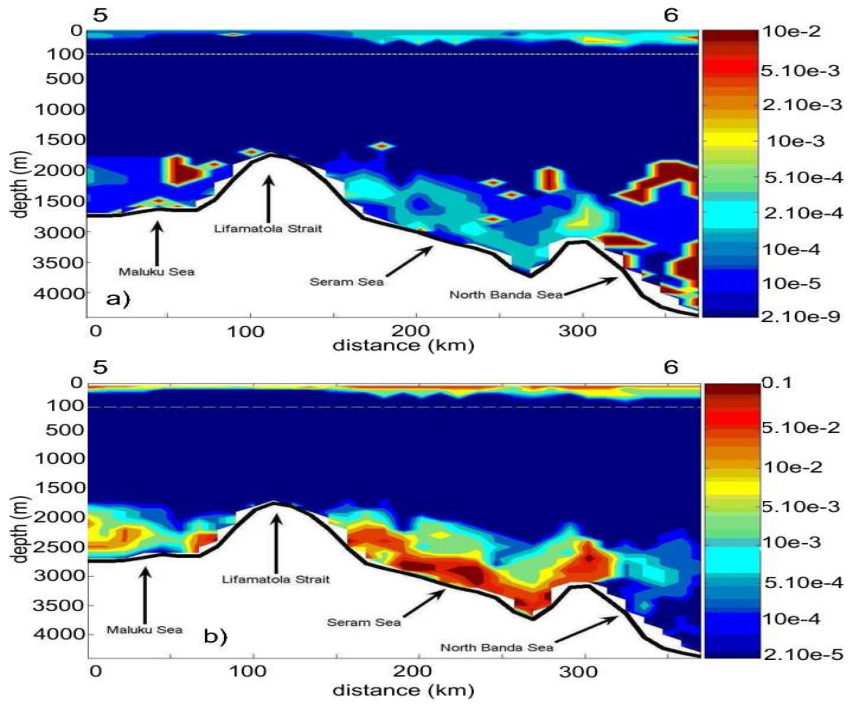

Fig. 4. Sections of (a) $q^{2}\left(\mathrm{~m}^{2} \mathrm{~s}^{-2}\right)$ and (b) $K_{\mathrm{M}}\left(\mathrm{m}^{2} \mathrm{~s}^{-1}\right)$ through the Lifamatola Sill. Locations of points 5 and 6 at the top of the figures are given in Fig. 1.
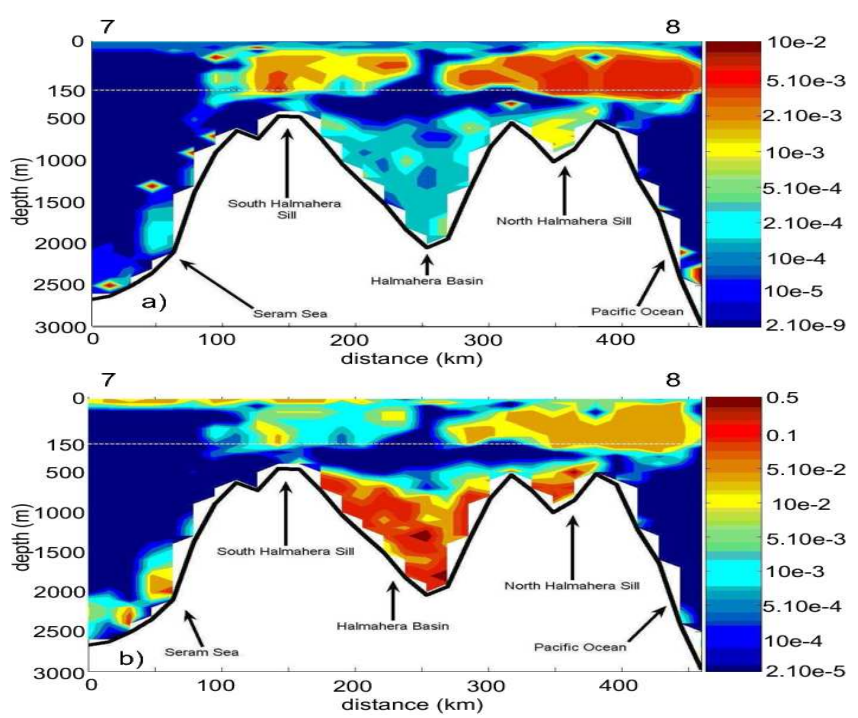

Fig. 5. Sections of (a) $q^{2}\left(\mathrm{~m}^{2} \mathrm{~s}^{-2}\right)$ and (b) $K_{\mathrm{M}}\left(\mathrm{m}^{2} \mathrm{~s}^{-1}\right)$ across the Halmahera Sea. Locations of points 7 and 8 at the top of the figures are given in Fig. 1.

becomes small within $100 \mathrm{~km}$ of the sloping topography. In the thermocline above $\sim 1000 \mathrm{~m}$, values of $10^{-8} \mathrm{~m}^{2} \mathrm{~s}^{-2}$ or less are seen, except around the Karakelong Basin and Ridge where maximum values of $\sim 2 \times 10^{-3} \mathrm{~m}^{2} \mathrm{~s}^{-2}$ are found in the upper $300 \mathrm{~m}$. In the upper mixed layer (UML), values of $\sim 2 \times 10^{-4} \mathrm{~m}^{2} \mathrm{~s}^{-2}$ are confined to the upper $50 \mathrm{~m}$.

The spatial pattern in $K_{\mathrm{M}}$ (Fig. 2b) and $K_{\mathrm{H}}$ (not shown) is very similar to $q^{2}$. Near sloping topography values of $K_{\mathrm{M}}$ are $\sim 10^{-2} \mathrm{~m}^{2} \mathrm{~s}^{-1}$ and often increase to $10^{-1}$ to $5 \times$ $10^{-1} \mathrm{~m}^{2} \mathrm{~s}^{-1}$ at the downstream slope. $K_{\mathrm{M}}$ values are $\sim 5 \times$ 
$10^{-3}-10^{-1} \mathrm{~m}^{2} \mathrm{~s}^{-1}$ in the Karakelong Basin. Moving away from topography, values of $K_{\mathrm{M}} \sim 5 \times 10^{-4} \mathrm{~m}^{2} \mathrm{~s}^{-1}$ are seen downstream of the North Sangihe Sill into the Sulawesi Sea, decreasing to the POM background value of $2 \times 10^{-5} \mathrm{~m}^{2} \mathrm{~s}^{-1}$ $200 \mathrm{~km}$ downstream. $K_{\mathrm{M}}$ is small in the thermocline except near the Karakelong Basin and Ridge where values reach $10^{-2} \mathrm{~m}^{2} \mathrm{~s}^{-1}$ between 200 and $300 \mathrm{~m}$.

Through the Dewakang Sill $q^{2}$ values of $10^{-4} \mathrm{~m}^{2} \mathrm{~s}^{-2}$ or greater are seen in the vicinity of the sill (Fig. 3a). These values extend to $200 \mathrm{~m}$ above the sill, increasing to $5 \times 10^{-3} \mathrm{~m}^{2} \mathrm{~s}^{-2}$ or more along the passage between the sill and the Flores Sea. Values are generally small along sloping topography. Higher values of $q^{2}$ extend through the water column over the Dewakang Sill. Away from topography values are reduced to $\sim 10^{-8} \mathrm{~m}^{2} \mathrm{~s}^{-2}$. Values in the UML are $\sim 5 \times 10^{-4} \mathrm{~m}^{2} \mathrm{~s}^{-2}$.

The pattern in $K_{\mathrm{M}}$ and $K_{\mathrm{H}}$ (not shown) is very similar to $q^{2}$. Maximum values of $K_{\mathrm{M}}$ are $\sim 5 \times 10^{-3}$ to $10^{-2} \mathrm{~m}^{2} \mathrm{~s}^{-1}$ downstream of the sill into the Flores Sea (Fig. 3b). Diffusivities are not very large along the upstream and downstream slopes and rapidly decrease to background values.

The section through the Lifamatola Passage (Fig. 4) extends from the South Maluku Sea (Batjan Basin) across the Seram Sea into the North Banda Sea. In deep water downslope and downstream of the Lifamatola Sill, $q^{2}$ values of $\sim 5 \times 10^{-5} \mathrm{~m}^{2} \mathrm{~s}^{-2}$ are seen (Fig. 4a). These values extend through the Seram Sea and into the North Banda Sea, reaching $5 \times 10^{-4} \mathrm{~m}^{2} \mathrm{~s}^{-2}$ in patches. Upstream in the Maluku Sea, large values are seen on the slope, and values of $q^{2}>5 \times 10^{-5} \mathrm{~m}^{2} \mathrm{~s}^{-2}$ are seen over a substantial area near the bottom of the basin. Values are small above sill depth. In the UML $q^{2}$ is $\sim 10^{-3} \mathrm{~m}^{2} \mathrm{~s}^{-2}$.

The pattern in both $K_{\mathrm{M}}$ and $K_{\mathrm{H}}$ (not shown) is similar to $q^{2}$. $K_{\mathrm{M}}$ values of $5 \times 10^{-2} \mathrm{~m}^{2} \mathrm{~s}^{-1}$ (Fig. 4 b) extend immediately downstream of the Lifamatola Sill to the North Banda Sea, with values as high as $10^{-1} \mathrm{~m}^{2} \mathrm{~s}^{-1}$ seen in patches. Large values are also seen in the Maluku Sea, upstream of the sill. Values are small above sill depth. In the UML values reach $10^{-2} \mathrm{~m}^{2} \mathrm{~s}^{-1}$.

The Halmahera Sea section extends from the Pacific Ocean to the Seram Sea. The largest values of $q^{2}$ of $\sim$ $5 \times 10^{-3} \mathrm{~m}^{2} \mathrm{~s}^{-2}-10^{-2} \mathrm{~m}^{2} \mathrm{~s}^{-2}$ are seen at the North Halmahera Sill in the upper $200 \mathrm{~m}$ and generally extend across the Halmahera Sea to the southern sill where values are slightly less (Fig. 5b). Below sill depth, $q^{2}$ is $\sim 10^{-4} \mathrm{~m}^{2} \mathrm{~s}^{-2}$ or more throughout the Halmahera Basin. Downstream of the south sill along the slope in the Seram Sea, values are $\sim 10^{-5} \mathrm{~m}^{2} \mathrm{~s}^{-2}$ or greater and can reach $5 \times 10^{-4} \mathrm{~m}^{2} \mathrm{~s}^{-2}$. Large values are also seen on the upstream slope in the Pacific Ocean. Away from topography $q^{2}$ is generally small. In the UML $q^{2}$ is $\sim 10^{-3} \mathrm{~m}^{2} \mathrm{~s}^{-2}$.

Patterns in $K_{\mathrm{M}}$ and $K_{\mathrm{H}}$ (not shown) are very similar to $q^{2}$. $K_{\mathrm{M}}$ is largest in the Halmahera Basin where values are $\sim 5 \times$ $10^{-3}$ to $10^{-1} \mathrm{~m}^{2} \mathrm{~s}^{-1}$ or more (Fig. $5 \mathrm{~b}$ ). In the upper $200 \mathrm{~m}$, $K_{\mathrm{M}}$ is $\sim 5 \times 10^{-3}-10^{-2} \mathrm{~m}^{2} \mathrm{~s}^{-1}$ at the Northern Halmahera

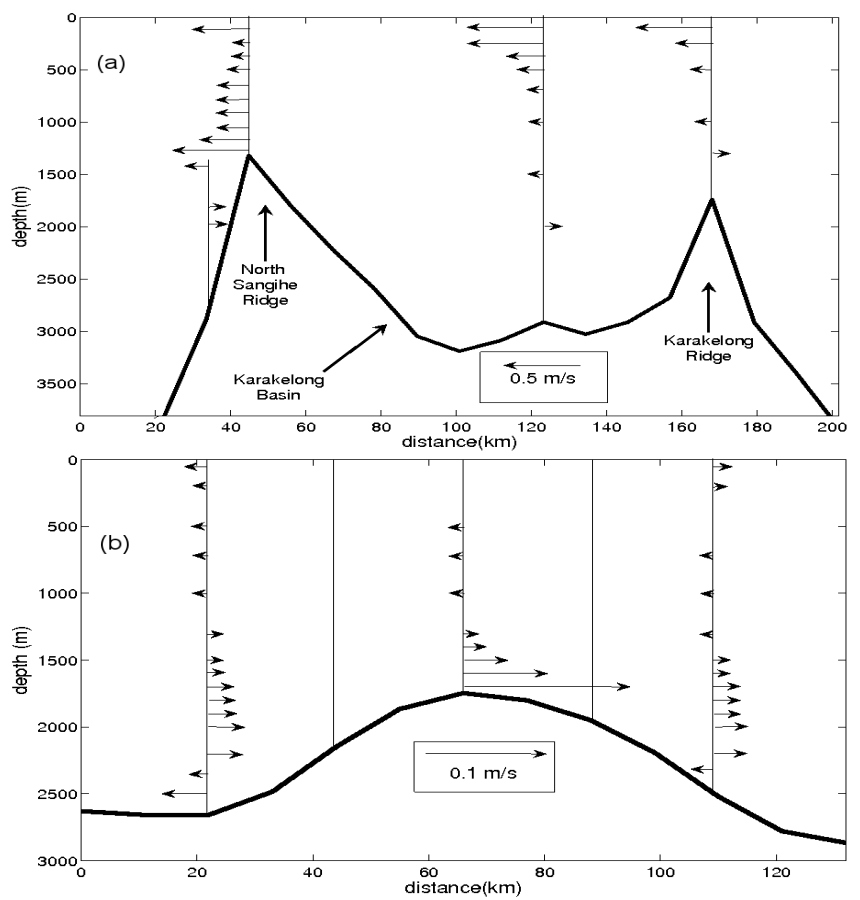

Fig. 6. (a) $u$ velocities in $\mathrm{ms}^{-1}$ at the section through the sill in the North Sangihe Ridge from east (right) to west (left), see Figs. 1 and 2 for location. (b) $v$ velocities in $\mathrm{m} \mathrm{s}^{-1}$ at the section through the Lifamatola Passage (at $i=138$ ) from north (South Maluku Sea, left, $j=154$ ) to south (Seram Sea, right, $j=146$ ), see Fig. 1 for $i, j$ coordinates and section location (thick black line). The five vertical lines in (b) show the locations of profiles presented and discussed in Sect. 4 of the paper. The distance referred to on the abscissa is essentially the distance across the sill from the Maluku Sea in the north to the Seram Sea in the south. The actual sill is located at the shallowest point in the section $(\sim 70 \mathrm{~km})$.

Sill and $\sim 10^{-3} \mathrm{~m}^{2} \mathrm{~s}^{-1}$ at the Southern Halmahera Sill. $K_{\mathrm{M}}$ is generally greater than $5 \times 10^{-4} \mathrm{~m}^{2} \mathrm{~s}^{-1}$ along the downstream slope. $K_{\mathrm{M}}$ is $\sim 10^{-3}$ in the upper mixed layer.

Our model results show that vertically sheared flows are mainly responsible for the large values of $q^{2}$ and, consequently, $K_{\mathrm{M}}$. This is seen at topographic features and in the thermocline in regions of known strong current. Figure 6 shows the shear flows seen around the North Sangihe Ridge and Lifamatola Strait areas. At the sill in the North Sangihe Ridge, the strongly sheared flow accounts for the turbulence at the sill (Fig. 6a) and causes this water to mix with warmer water above it, thereby setting up a baroclinic pressure gradient and ensuring the continued overflow across the sill. The velocity shear along the downstream slope allows water to enter the deep Sulawesi Sea. Thus, the relatively warm water of the deep Sulawesi basin as observed by Gordon et al. (2003).A similar set of processes occurs at the Lifamatila Sill, allowing relatively warm water to penetrate the deeper Seram Sea (Fig. 6b). O'Driscoll and Kamenkovich (2009) found that a very steep temperature gradient exists in 


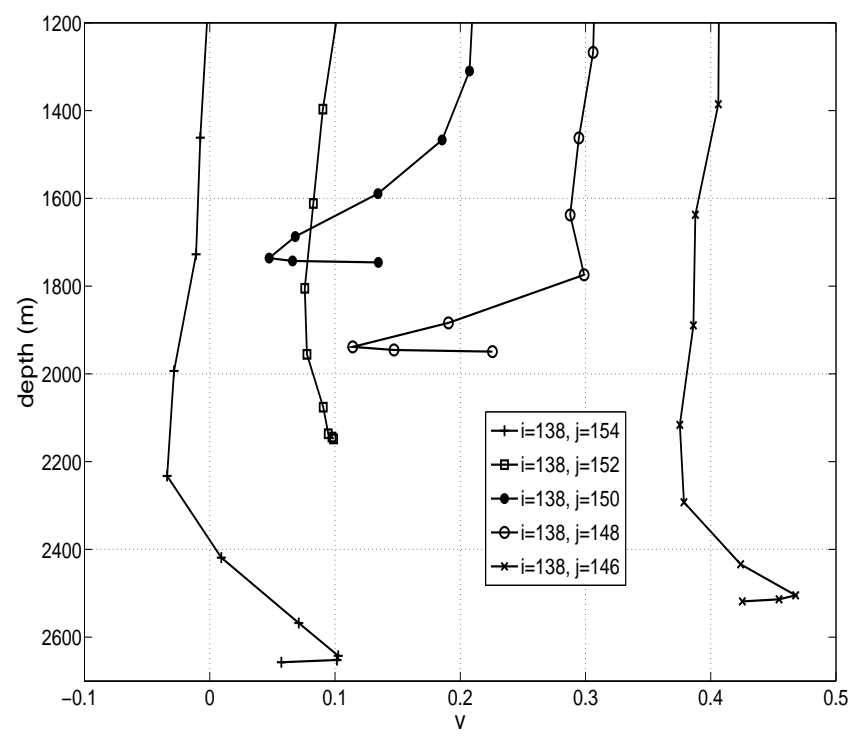

Fig. 7. Profiles of $v$ component of velocity $\left[\mathrm{m} \mathrm{s}^{-1}\right]$ at the section through the Lifamatola Passage $(i=138)$ from north $(j=154$, left) to south $(j=146$, right), represented as a thick black line in Fig. 1. Profiles are offset for clarity: for $j=154$ offset is $0.0 \mathrm{~m} \mathrm{~s}^{-1}$; for $j=152$ offset is $0.1 \mathrm{~m} \mathrm{~s}^{-1}$; for $j=150$ offset is $0.2 \mathrm{~m} \mathrm{~s}^{-1}$; for $j=148$ offset is $0.3 \mathrm{~m} \mathrm{~s}^{-1}$; for $j=146$ offset is $0.4 \mathrm{~m} \mathrm{~s}^{-1}$. See Fig. 1 for $i$ and $j$ coordinates and Fig. $6 \mathrm{~b}$ for profile locations. Vertical and horizontal lines are shown for convenience.

the downstrean direction across the Lifamatola Sill. Polzin et al. (1996) observed similar processes that accompany the spreading of Antarctic Bottom Water at the Romanche fracture zone in the equatorial Atlantic Ocean.

In the thermocline, strong shear flows are found around the North Sangihe Ridge region (Fig. 6a) in the Mindanao Current. These shear flows result in large values of $q^{2}$ and coefficients of vertical turbulent mixing (Fig. 2), and the signature of NPW is transformed by mixing, reducing the thermocline $S_{\max }$ signature, while increasing the subthermocline $S_{\min }$ signature of North Pacific Intermediate Water.

\section{Detailed analysis of turbulence characteristics around the Lifamatola Sill}

First, consider Fig. 6b again, which gives a vertical section of $v$ velocities through the Lifamatola Sill, and shows a southward flow extending from below $1200 \mathrm{~m}$ to the bottom through the sill. Model simulated deep water transports across the sill below $1200 \mathrm{~m}$ are in good agreement with those given by van Aken et al. (1988), who calculated a deep southward transport of $\sim 1.5 \mathrm{~Sv}$ from a current mooring deployed between January and March 1985, while model deep southward transport was approximately $1.4 \mathrm{~Sv}$ in February (Kamenkovich et al., 2009). In the same paper, van Aken et al. (1988) estimated an annual deep transport of the order of $1 \mathrm{~Sv}$, in good agreement with the model (see Kamenkovich et al., 2009). However, later on van Aken et al. (2009) calculated a long-term mean deep transport of 2.4-2.5 Sv for 34 months between 2004 and 2006 from a mooring containing current meters and ADCPs at the sill as part of the INSTANT program (see Sprintall et al., 2004). The authors in van Aken et al. (2009) state that the reduced transport estimated in van Aken et al. (1988) is due partly to the shorter observation period and partly to the smaller thickness of the overflow layer estimated from linear extrapolation. So some uncertainty remains in estimating deep transport through the Lifamatola Strait. The simulated structure of the velocity profile is in very good agreement with that observed by van Aken et al. (1988). All models have some tuning parameters to make numerical values compatible with observations. Therefore, we argue that the comparison of structures of the velocity profiles is more important than that of some numerical values. At the sill, southward velocities increase with depth to a maximum value of over $0.15 \mathrm{~m} \mathrm{~s}^{-1}$ at $\sim 1700 \mathrm{~m}$. Model velocities across the sill are in good agreement with those of Broecker et al. (1986), who found mean velocities of $\sim 20 \mathrm{~cm} \mathrm{~s}^{-1}$ just above the sill over a 28 day period in August-September 1976. However, they are less than those measured by van Aken et al. (1988), who found mean velocities of $61 \mathrm{~cm} \mathrm{~s}^{-1}$ at $60 \mathrm{~m}$ above the bottom in JanuaryMarch 1985, and van Aken et al. (2009), who found maximum velocities of $65 \mathrm{~cm} \mathrm{~s}^{-1}$ at $\sim 70 \mathrm{~m}$ above the bottom. Simulated $v$ velocities are also southward below sill depth, north and south of the sill, to a depth of $\sim 2400 \mathrm{~m}$. Velocity is northward below $\sim 2400 \mathrm{~m}$ both north and south of the sill. A weak northward current is seen to extend from $1200 \mathrm{~m}$ into the thermocline across the entire section. Note that all model results presented are from the 15 August after $15 \mathrm{yr}$ of model run.

$v$ velocity profiles through the sill below $1200 \mathrm{~m}$ are shown in detail in Fig. 7. It is seen that the southward current at the sill (middle ( $3 \mathrm{rd}$ ) profile, •) extends from $1300 \mathrm{~m}$ to the bottom and maximum velocity is seen at about $1700 \mathrm{~m}$ or deeper, below which velocity rapidly decreases. The observed mean profile shows southward flow across the sill at $129^{\circ}$ clockwise from north and into the Seram Sea. This practically coincides with the $y$ component of model flow across the sill, since the model domain is rotated anticlockwise relative to north-south, see Fig. 1. The profile to the south of the sill (4th profile, o) is similar to that at the sill, but the southward current is deeper because of the greater depth, and reaches a greater maximum velocity of almost $0.20 \mathrm{~m} \mathrm{~s}^{-1}$ just above the bottom. Moving into deeper water, both south and north, the southward (negative) current is not as strong as at the sill but extends to deeper than $2000 \mathrm{~m}$ in all cases. Currents are strongly northward (positive) below $\sim 2400 \mathrm{~m}$ at the deepest profiles (1st and 5th profiles), extending through the lower $200-300 \mathrm{~m}$ of the water column. Note also the rapid change of velocity (decrease in magnitude) just above the bottom in all profiles which is due to the 


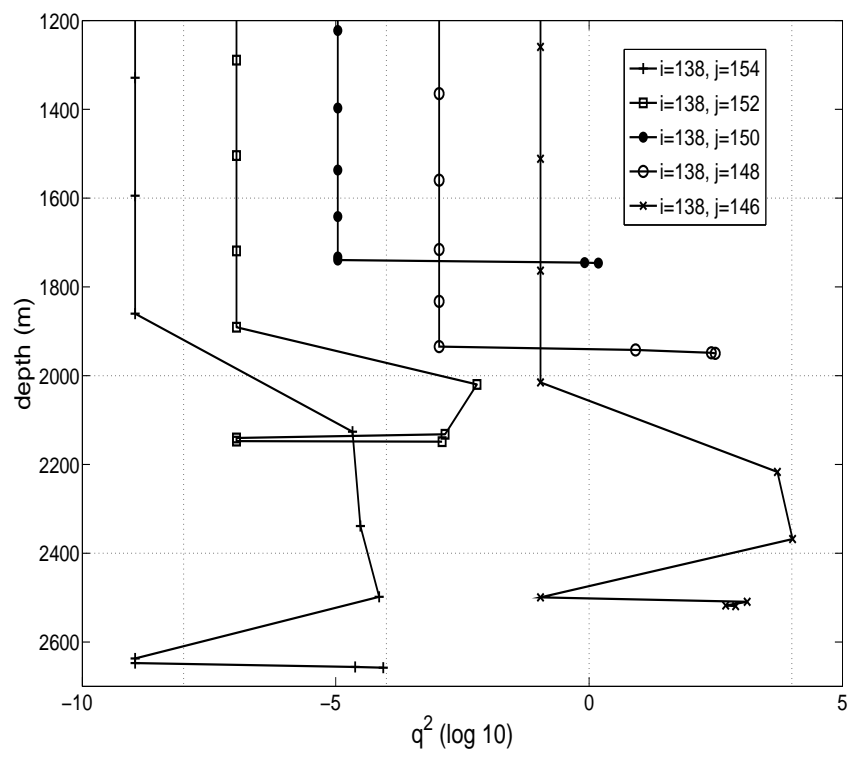

Fig. 8. Profiles of $q^{2}\left(\mathrm{~m}^{2} \mathrm{~s}^{-2}\right)$, twice the turbulence kinetic energy (TKE), through the Lifamatola Passage $(i=138)$ from north $(j=154)$ to south $(j=146)$. Decimal logarithmic scale is used along the horizontal axis. Profiles are offset for clarity: for $j=154$, offset $=0$; for $j=152$, offset $=2$ (or $q^{2}$ is multiplied by $10^{2}$ ); for $j=150$, offset $=4$ (or $q^{2}$ is multiplied by $10^{4}$ ); for $j=148$, offset $=6$ (or $q^{2}$ is multiplied by $10^{6}$ ); for $j=146$, offset $=8$ (or $q^{2}$ is multiplied by $10^{8}$ ). See Fig. 1 for $i, j$ coordinates. See Fig. $6 \mathrm{~b}$ for profile location through sill. Vertical and horizontal lines are shown for convenience.

bottom boundary condition used in the POM,

$K_{m} \frac{\partial v}{\partial z}=C_{z}\left(u^{2}+v^{2}\right)^{1 / 2} v \quad$ at $\quad z=-H$.

From Eq. (14) it follows that if $v(-H)>0$, then $\frac{\partial v}{\partial z}(-H)>0(1 \mathrm{st}$ and 5 th profiles); if $v(-H)<0$, then $\frac{\partial v}{\partial z}(-H)<0$ (3rd and 4 th profiles). In the case of the 2 nd profile, $v(-H)$ is close to zero. This rapid change in velocity is present in the observed profile (see van Aken et al., 2009 Fig. 3), which suggests that the bottom boundary condition Eq. (14) is quite adequate.

We analyzed vertical profiles of turbulence characteristics at five locations across the sill. Profiles of $q^{2}$ are shown in Fig. 8. At the sill (3rd profile, $\bullet$ ), large values of $q^{2}$ are confined to the very bottom of the water column, above which values are rapidly reduced and are set to the model background value of $10^{-9} \mathrm{~m}^{2} \mathrm{~s}^{-2}$. A similar profile is seen to the south of the sill (4th profile, o). This feature is also seen in the other three profiles. However, in addition, at these three profiles (1st, 2nd, 5th) large values of $q^{2}$ extend upward for several hundred meters above the bottom: between 1900$2600 \mathrm{~m}$ in the 1 st profile (+), $1900-2100 \mathrm{~m}$ in the 2nd profile $(\square)$, and $2000-2500 \mathrm{~m}$ in the 5 th profile $(\times)$. Above this

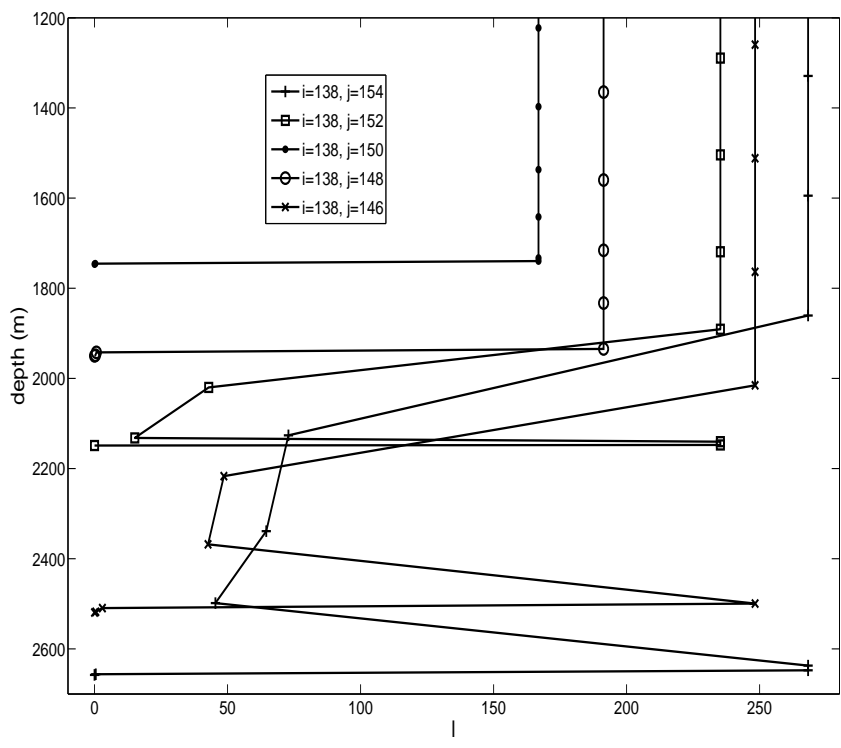

Fig. 9. Turbulence length scale, $\ell[m]$, for the five profiles considered.

layer $q^{2}$ are also small and are set to the model background value. The increase in $q^{2}$ above the bottom (1st, 2 nd, and 5 th profiles) is reasonable because the intensity of turbulence should first increase, as one moves downwards, and then decrease at the very bottom. However, due to the increase of velocity shear at the very bottom and ensuing shear production of $q^{2}$, the pronounced increase in $q^{2}$ values occurs near the very bottom (see Table 1$)$.

Profiles of $q^{2} \ell$ (not shown) are very similar to $q^{2}$ profiles (Fig. 8), except close to the bottom boundary. The analogous structures of Eqs. (7) and (10) explain this similarity, while the difference in bottom boundary conditions, Eq. (12), explains the additional rapid change (decrease) of $q^{2} \ell$ near the bottom. Yet, the real question is whether the distribution of $\ell$ that is determined by distributions of $q^{2}$ and $q^{2} \ell$ is reasonable (see Fig. 9).

How are $q^{2}$ and $q^{2} \ell$ generated? To answer this question, we estimated separately all terms in Eqs. (7) and (10) to reveal the leading terms (see Tables 1 and 2). It is worth noting that these tables are calculated only for those $\sigma$ levels for which $q^{2}$ and $q^{2} \ell$ are greater than $10^{-9}$, the point being that if $q^{2}$ and $q^{2} \ell$ calculated from Eqs. (7) and (10) are less than this value, the POM replaces them with $10^{-9}$ in the $S I$ system. Therefore, the analysis of contributions of different terms in Eqs. (7) and (10) at these levels is meaningless. Tables 1 and 2 give estimates of the separate terms in Eqs. (7) and (10) at the same 5 profiles across the sill from the bottom, $\sigma(k b)$, where $k b=29$, up to a depth of 0.8 times water column depth, $\sigma(k b-6)$. Recalling that values of $\sigma$ range from 0 at the surface to -1 at the ocean bottom, we chose the following $\sigma$ values: $\sigma(k b-6)=-0.80$; $\sigma(k b-5)=-0.88 ; \sigma(k b-4)=-0.94 ; \sigma(k b-3)=-0.9922$; 
Table 1. Near bottom values of different terms of the $q^{2}$ Eq. (7) at 5 points (location indices are given) across the Lifamatola Sill as follows: rate of time difference (td), 3-D advection (ad), shear production (sp), work of buoyancy forces (bp), dissipation (dp), vertical diffusion (vd), and horizontal diffusion (hd) and the difference between the left-hand side and right-hand side of Eq. (7) $(\mathrm{resid}), \mathrm{where} \mathrm{resid}=\mathrm{td}+\mathrm{ad}-(\mathrm{vd}+$ $\mathrm{sp}+\mathrm{bp}+\mathrm{dp}+\mathrm{hd})$. Leading terms are indicated by bold. All units in $\mathrm{m}^{2} \mathrm{~s}^{-3}$.

\begin{tabular}{|c|c|c|c|c|c|c|c|c|}
\hline$\sigma$ & td & $\mathrm{ad}$ & $\mathrm{sp}$ & bp & $\mathrm{dp}$ & $\mathrm{vd}$ & hd & resid \\
\hline & (a) & $i=138$ & $j=154$ & & & & & \\
\hline$\sigma(k b-6)$ & $-9.0 \mathrm{e}-11$ & $2.9 \mathrm{e}-11$ & $2.6 e-13$ & $-1.8 \mathrm{e}-11$ & $-1.6 e-11$ & $2.5 e-13$ & $-2.7 e-11$ & $-1.4 \mathrm{e}-15$ \\
\hline$\sigma(k b-5)$ & $-2.0 e-10$ & $-3.7 e-12$ & $1.8 \mathrm{e}-10$ & $-7.2 \mathrm{e}-11$ & $-3.1 e-10$ & $2.9 \mathrm{e}-12$ & $-1.1 \mathrm{e}-11$ & $9.5 e-16$ \\
\hline$\sigma(k b-4)$ & $-6.3 e-10$ & $-3.6 e-10$ & $3.8 \mathrm{e}-10$ & $-3.2 \mathrm{e}-10$ & $-1.5 \mathrm{e}-9$ & $-7.3 \mathrm{e}-12$ & $4.7 \mathrm{e}-10$ & $-3.7 \mathrm{e}-15$ \\
\hline$\sigma(k b-3)$ & $2.2 \mathrm{e}-10$ & $5.0 \mathrm{e}-11$ & $1.4 \mathrm{e}-12$ & $-8.0 \mathrm{e}-12$ & $-4.4 \mathrm{e}-16$ & $6.4 \mathrm{e}-12$ & $2.7 e-10$ & $6.7 \mathrm{e}-17$ \\
\hline$\sigma(k b-2)$ & $6.7 \mathrm{e}-10$ & $-4.3 e-10$ & $5.4 \mathrm{e}-13$ & $-2.8 \mathrm{e}-11$ & $-1.3 e-15$ & $6.9 \mathrm{e}-11$ & $1.9 \mathrm{e}-10$ & $-5.4 \mathrm{e}-17$ \\
\hline \multirow[t]{2}{*}{$\sigma(k b-1)$} & $5.1 \mathrm{e}-10$ & $-3.8 \mathrm{e}-10$ & $2.9 \mathrm{e}-8$ & $-3.4 \mathrm{e}-10$ & -3.1-e-8 & $1.8 \mathrm{e}-9$ & $9.2 \mathrm{e}-11$ & $2.1 \mathrm{e}-15$ \\
\hline & (b) & $i=138$ & $j=152$ & & & & & \\
\hline$\sigma(k b-4)$ & $-1.5 e-10$ & $2.4 \mathrm{e}-10$ & $2.7 \mathrm{e}-11$ & $-1.1 \mathrm{e}-10$ & $-1.3 e-10$ & $-2.9 \mathrm{e}-13$ & $3.1 \mathrm{e}-10$ & $-5.7 \mathrm{e}-15$ \\
\hline$\sigma(k b-3)$ & $-3.6 e-11$ & $1.1 \mathrm{e}-10$ & $1.4 \mathrm{e}-11$ & $-4.8 \mathrm{e}-11$ & $-4.3 e-11$ & $-7.4 \mathrm{e}-13$ & $1.5 \mathrm{e}-10$ & $-1.2 \mathrm{e}-14$ \\
\hline$\sigma(k b-1)$ & $1.8 \mathrm{e}-12$ & 1.1e-10 & $8.3 e-12$ & $-9.0 e-11$ & $-6.8 e-18$ & 7.8e-11 & $1.2 \mathrm{e}-10$ & $-1.8 \mathrm{e}-13$ \\
\hline \multirow[t]{2}{*}{$\sigma(k b-1)$} & $\begin{array}{c}(\mathrm{c}) \\
5.4 \mathrm{e}-9\end{array}$ & $\begin{array}{c}i=138 \\
1.3 \mathrm{e}-9\end{array}$ & $\begin{array}{c}j=150 \\
\mathbf{3 . 2 e}-7\end{array}$ & $-1.2 \mathrm{e}-9$ & $-3.2 \mathrm{e}-7$ & 4.6e-9 & $6.7 \mathrm{e}-11$ & $-8.0 \mathrm{e}-12$ \\
\hline & (d) & $i=138$ & $j=148$ & & & & & \\
\hline$\sigma(k b-2)$ & $1.6 \mathrm{e}-10$ & $2.5 \mathrm{e}-10$ & $2.1 \mathrm{e}-9$ & $-1.6 \mathrm{e}-9$ & $-4.0 \mathrm{e}-9$ & $3.6 e-9$ & $3.1 \mathrm{e}-10$ & $-6.5 e-14$ \\
\hline \multirow[t]{2}{*}{$\sigma(k b-1)$} & $7.3 \mathrm{e}-9$ & $1.0 \mathrm{e}-9$ & $1.5 \mathrm{e}-6$ & $-9.8 \mathrm{e}-10$ & $-1.5 e-6$ & $-7.6 \mathrm{e}-10$ & $-1.6 \mathrm{e}-10$ & $1.6 e-13$ \\
\hline & (e) & $i=138$ & $j=146$ & & & & & \\
\hline$\sigma(k b-6)$ & $5.5 e-11$ & $-9.4 e-11$ & $1.3 e-13$ & $-5.2 \mathrm{e}-11$ & $-1.2 \mathrm{e}-16$ & $5.1 \mathrm{e}-14$ & 1.1e-11 & $-5.6 e-17$ \\
\hline$\sigma(k b-5)$ & $-2.0 \mathrm{e}-12$ & $-2.4 e-10$ & $1.2 \mathrm{e}-11$ & $-1.0 \mathrm{e}-10$ & $-9.3 e-11$ & $6.9 \mathrm{e}-14$ & $-6.2 \mathrm{e}-11$ & $1.8 \mathrm{e}-15$ \\
\hline$\sigma(k b-4)$ & $-7.5 e-11$ & $6.1 \mathrm{e}-11$ & $5.4 \mathrm{e}-10$ & $-1.8 \mathrm{e}-10$ & $-3.0 \mathrm{e}-10$ & $-5.4 \mathrm{e}-13$ & $-7.9 \mathrm{e}-11$ & $-1.5 e-15$ \\
\hline$\sigma(k b-2)$ & $5.8 \mathrm{e}-11$ & $-4.4 e-10$ & $1.7 \mathrm{e}-9$ & $-2.0 \mathrm{e}-10$ & $-2.0 \mathrm{e}-9$ & $-1.7 e-10$ & $2.5 \mathrm{e}-10$ & $-4.9 \mathrm{e}-12$ \\
\hline$\sigma(k b-1)$ & $1.0 \mathrm{e}-13$ & $-1.4 \mathrm{e}-1-0$ & $2.1 \mathrm{e}-9$ & $-5.6 e-12$ & $-2.7 \mathrm{e}-9$ & $2.0 \mathrm{e}-10$ & $2.7 \mathrm{e}-10$ & $-3.3 e-16$ \\
\hline
\end{tabular}

$\sigma(k b-2)=-0.9961 ; \sigma(k b-1)=-0.9994$. The relatively large number of $\sigma$ levels close to the bottom allows for a reasonable description of a bottom boundary layer.

Table 1 shows that at all 5 profiles except the 2nd, shear production of $q^{2}$ and its dissipation are leading factors at levels very close to the bottom (due to increased velocity gradient at these levels, see Fig. 7). At other levels, such a balance of terms in Eq. (7) is not observed. There are levels and profiles at which any and all terms in Eq. (7) can be important. Nevertheless, it is worth noting that the vertical diffusion of $q^{2}$ is important at one level of the 2nd, 4th and 5th profiles only, while horizontal diffusion is important at more levels (especially in profiles 1 and 2). The work of buoyancy forces is basically unimportant at profile 1 only.

It is appropriate to discuss now profiles of shear production (Fig. 10), the work of buoyancy forces (Fig. 11) and dissipation of $q^{2}$ (Fig. 12). For shear production, we see first that values increase as one moves downwards towards the bottom, then decrease above the bottom before finally increasing substantially very close to the bottom (except profile 2), which is certainly due to the increase in velocity shear close to the bottom (Fig. 7). Notice that velocity shear is small at profile 2. Note also, in Fig. 7, there is very little shear just above the bottom points, particularly in profiles 1 and 2 . This

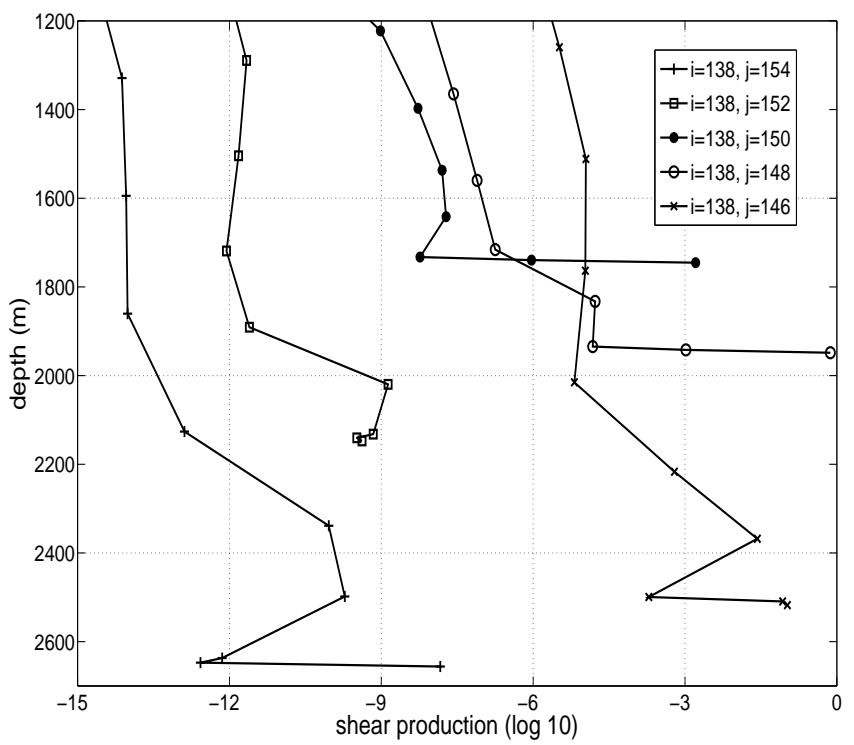

Fig. 10. Profiles of $\mathrm{sp}\left(\mathrm{m}^{2} \mathrm{~s}^{-3}\right)$, i.e. shear production of $q^{2}$. Note that profiles are offset as in Fig. 8. 
Table 2. Same as Table 1 but for $q^{2} \ell$.

\begin{tabular}{|c|c|c|c|c|c|c|c|c|}
\hline$\sigma$ & $\mathrm{td}$ & ad & $\mathrm{sp}$ & bp & $\mathrm{dp}$ & $\mathrm{vd}$ & hd & resid \\
\hline & (a) & $i=138$ & $j=154$ & & & & & \\
\hline$\sigma(k b-6)$ & $-4.6 e-9$ & $3.6 e-9$ & $1.7 \mathrm{e}-11$ & $-1.2 \mathrm{e}-9$ & $-7.4 \mathrm{e}-10$ & $1.1 \mathrm{e}-11$ & $-1.8 \mathrm{e}-9$ & $-8.7 \mathrm{e}-15$ \\
\hline$\sigma(k b-5)$ & $-9.6 e-9$ & $4.9 \mathrm{e}-9$ & $1.1 \mathrm{e}-8$ & $-4.2 \mathrm{e}-9$ & $-1.4 \mathrm{e}-8$ & $8.7 \mathrm{e}-11$ & $-5.8 \mathrm{e}-10$ & $-1.7 \mathrm{e}-13$ \\
\hline$\sigma(k b-4)$ & $-2.2 \mathrm{e}-8$ & $-1.1 \mathrm{e}-8$ & $1.6 \mathrm{e}-8$ & $-1.3 e-8$ & $-6.0 \mathrm{e}-8$ & $-2.7 \mathrm{e}-10$ & $1.9 \mathrm{e}-8$ & $-8.9 \mathrm{e}-13$ \\
\hline$\sigma(k b-1)$ & $-5.8 \mathrm{e}-11$ & $-2.8 \mathrm{e}-10$ & $1.2 \mathrm{e}-8$ & $-1.4 \mathrm{e}-10$ & $-1.2 \mathrm{e}-8$ & $-3.8 \mathrm{e}-10$ & $9.6 e-11$ & $-2.1 \mathrm{e}-11$ \\
\hline & (b) & $i=138$ & $j=152$ & & & & & \\
\hline$\sigma(k b-4)$ & $-3.5 e-9$ & $1.0 \mathrm{e}-8$ & $1.1 \mathrm{e}-9$ & $-4.0 \mathrm{e}-9$ & $-5.4 \mathrm{e}-9$ & $-1.4 \mathrm{e}-11$ & $1.3 \mathrm{e}-8$ & $-1.7 \mathrm{e}-14$ \\
\hline$\sigma(k b-3)$ & $-3.2 \mathrm{e}-11$ & $-6.7 e-10$ & $1.9 \mathrm{e}-10$ & $-6.5 e-10$ & $-2.2 \mathrm{e}-9$ & $-8.0 \mathrm{e}-13$ & $1.8 \mathrm{e}-9$ & $-2.8 \mathrm{e}-12$ \\
\hline$\sigma(k b-1)$ & $\begin{array}{c}\text { (c) } \\
9.2 \mathrm{e}-10\end{array}$ & $\begin{array}{l}i=138 \\
4.3 \mathrm{e}-10\end{array}$ & $\begin{array}{c}j=150 \\
\mathbf{1 . 2 e - 8}\end{array}$ & $-3.3 e-10$ & $-8.1 \mathrm{e}-8$ & $-2.9 \mathrm{e}-9$ & $3.0 \mathrm{e}-11$ & $-1.6 \mathrm{e}-9$ \\
\hline & (d) & $i=138$ & $j=148$ & & & & & \\
\hline$\sigma(k b-2)$ & $2.1 \mathrm{e}-11$ & $7.5 e-10$ & $1.3 \mathrm{e}-9$ & $-9.9 e-10$ & $-1.5 \mathrm{e}-9$ & $1.2 \mathrm{e}-9$ & $7.1 \mathrm{e}-10$ & $-9.8 \mathrm{e}-12$ \\
\hline$\sigma(k b-1)$ & $1.5 \mathrm{e}-9$ & $3.9 \mathrm{e}-10$ & $4.8 \mathrm{e}-7$ & $-3.1 \mathrm{e}-10$ & $-4.5 e-7$ & $-1.5 \mathrm{e}-8$ & $-4.1 \mathrm{e}-11$ & $-2.7 e-11$ \\
\hline & (e) & $i=138$ & $j=146$ & & & & & \\
\hline$\sigma(k b-5)$ & $2.1 e-9$ & $-9.7 e-9$ & $5.4 \mathrm{e}-10$ & $-4.4 \mathrm{e}-9$ & $-2.9 \mathrm{e}-9$ & $1.7 \mathrm{e}-12$ & $-2.9 \mathrm{e}-9$ & $-6.0 \mathrm{e}-14$ \\
\hline$\sigma(k b-4)$ & $2.0 \mathrm{e}-10$ & $3.3 e-9$ & $2.1 e-8$ & $-6.7 e-9$ & $-1.1 \mathrm{e}-8$ & $-2.2 \mathrm{e}-11$ & $-2.8 \mathrm{e}-9$ & $-7.5 \mathrm{e}-14$ \\
\hline$\sigma(k b-2)$ & $1.4 \mathrm{e}-10$ & $-1.3 e-9$ & $4.5 \mathrm{e}-9$ & $-5.3 e-10$ & $-5.1 \mathrm{e}-9$ & $-6.1 \mathrm{e}-10$ & $7.6 e-10$ & $-2.4 \mathrm{e}-10$ \\
\hline$\sigma(k b-1)$ & $1.1 \mathrm{e}-11$ & $3.9 \mathrm{e}-10$ & $9.3 e-10$ & $-2.5 e-12$ & $-1.8 \mathrm{e}-9$ & $6.0 \mathrm{e}-10$ & $1.2 \mathrm{e}-10$ & $-5.2 \mathrm{e}-12$ \\
\hline
\end{tabular}

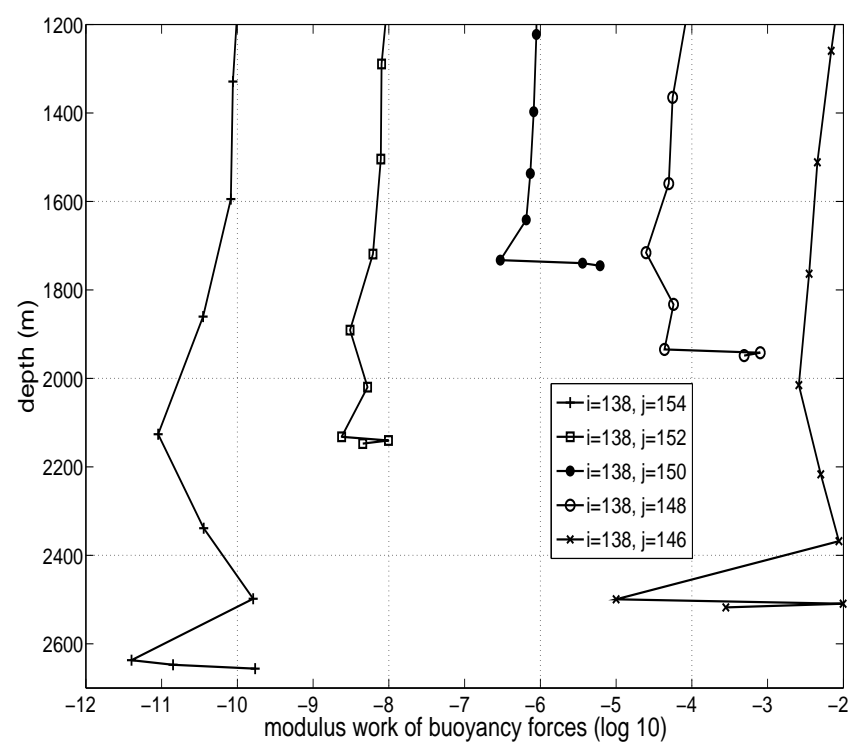

Fig. 11. Profiles of bp, i.e. modulus of work of buoyancy forces or modulus of buoyancy production $\left(\mathrm{m}^{2} \mathrm{~s}^{-3}\right)$. Note, that values of $\mathrm{bp}$ are always negative. Profiles are offset as in Fig. 8.

lack of shear combined with the little or no shear at these depths in the $u$ component of velocity (not shown) explains the reduction in shear production here. The work of buoyancy forces is the product of buoyancy frequency, $N^{2}$, with the mixing coefficient, $K_{\mathrm{H}}$, (Eq. 6). Values decrease gradually from $1200 \mathrm{~m}$ down through the water column. However, there is an increase in values of profiles 1 (between

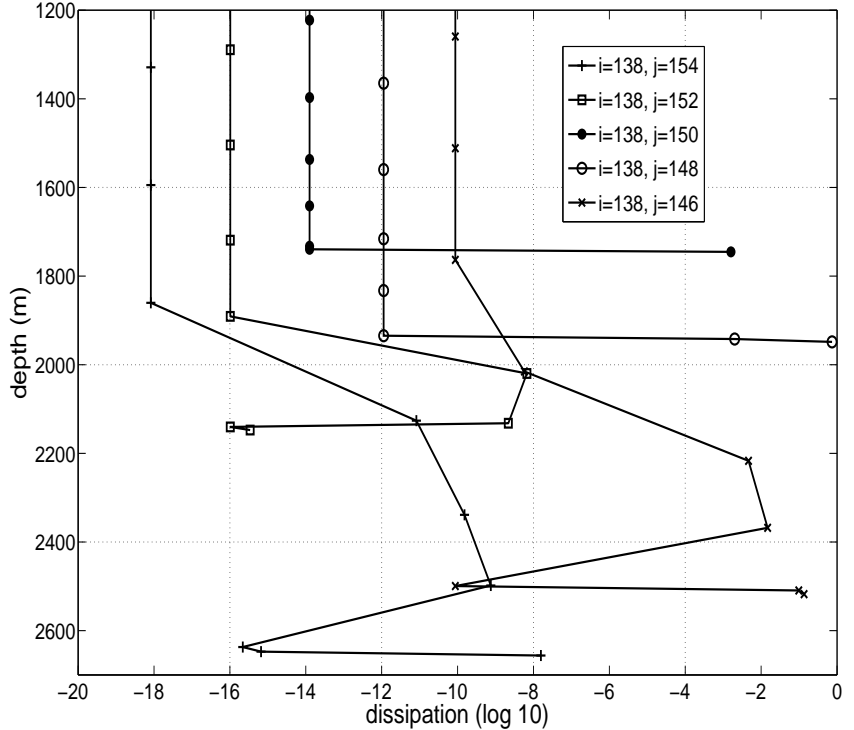

Fig. 12. Profiles of $\mathrm{dp}\left(\mathrm{m}^{2} \mathrm{~s}^{-3}\right)$, i.e. dissipation of $q^{2}$. Profiles are offset as in Fig. 8.

2100-2500 m), 2 (between 1900-2100 m), 4 (between 1700$1900 \mathrm{~m}$ ), and 5 (between 2000-2400 m). Values for all profiles increase rapidly just above the bottom. In the region of gradually decreasing values, buoyancy frequency also decreases gradually (not shown) while $K_{\mathrm{H}}$ is essentially constant (Fig. 14). The increase in the work of buoyancy forces above the bottom in profiles 1,2 , and 5 is due to the increase in $q^{2}$ and the subsequent increase in $K_{\mathrm{H}}$, while the increase in 


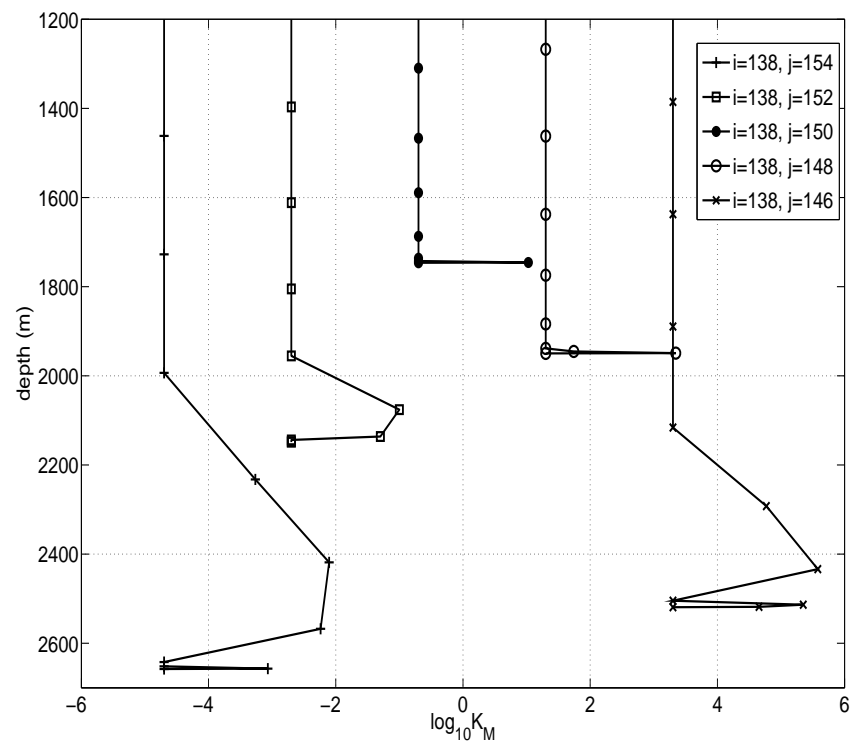

Fig. 13. Profiles of the coefficient of vertical diffusion of momentum, $K_{\mathrm{M}}\left(\mathrm{m}^{2} \mathrm{~s}^{-1}\right)$. Profiles are offset as in Fig. 8.

profile 4 is due to the increase in $N^{2}$. The increase in magnitude of dissipation close to the bottom is due to the combined effect of increased $q^{2}$ with decreased $\ell$, while the increase just above this is due to the combined effect of decreased $q^{2}$ with increased $\ell$.

Consider now profiles of the turbulence length scale $\ell$. From a general standpoint, we should expect to see constant values in the main depth of the ocean, with a gradual decrease as one moves toward the bottom. In fact, in Fig. 9, constant values are seen at all profiles in the main depth of the ocean, away from the effect of bottom topography, but the structure of $\ell$ at profiles 1,2 and 5 is unreasonably complicated when one moves toward the bottom. It is difficult to find any physical arguments to explain the rapid increase of $\ell$ below the decrease seen in these profiles. We can ascribe this behavior to the rather complicated structure of $q^{2} \ell$ in these profiles provided by Eq. (10), which is also difficult to explain with physical arguments. We think that the procedure for calculation of $\ell$ suggested by the POM does not provide the adequate behavior of $\ell$ within the bottom boundary layer. However, taking into account the adequate reproduction of dynamical characteristics, we argue that some inconsistencies in the calculation of $\ell$ and connected with $\ell$ characteristics, e.g. the Richardson number, etc., do not influence the dynamic characteristics substantially.

Profiles of magnitude of buoyancy frequency squared, $N^{2}$ (not shown), show that values decrease slowly as we move down below $1200 \mathrm{~m}$, as expected in the open ocean. However, profile 1 shows values increasing notably between 2300 and $2600 \mathrm{~m}$. This is due to strengthening stratification there, as shown in O'Driscoll and Kamenkovich (2009) ( their Fig. 13, profile C and Fig. $24 \theta-S$ diagram) and as previously ob- served by van Aken et al. (1988) their Fig. $7 \theta-S$ diagram). Rapid changes of $N^{2}$ close to the bottom are probably due to some drawbacks of the POM algorithm for calculation of $N^{2}$ in the deep ocean.

Profiles of the modulus of the Richardson number, $|R i|$, (see Eq. 2) (not shown) exhibit some rapid changes close to the bottom. In profiles 1 and 5, a rapid increase just above the bottom followed by a rapid decrease is due to the combination of rapidly increasing and decreasing $\ell$ with rapidly decreasing and increasing $q^{2}$, respectively, and is also seen in profile 2 to a lesser extent.

Finally, profiles of mixing coefficients $K_{\mathrm{M}}$ and $K_{\mathrm{H}}$ are provided in Figs. 13 and 14, respectively, (see Eq. 1). At the very bottom, $\ell=0$ due to the model bottom boundary condition, and $K_{\mathrm{M}}$ and $K_{\mathrm{H}}$ have model background values only. Above the bottom, $K_{\mathrm{M}}$ and $K_{\mathrm{H}}$ are large for a very thin layer because $q, S_{\mathrm{M}}$ and $S_{\mathrm{H}}$ are large, and $\ell$ is nonzero. Above this again, $K_{\mathrm{M}}$ and $K_{\mathrm{H}}$ are briefly small in the two deepest profiles, which is explained by small values of $q$ and $S_{\mathrm{M}}$ and $S_{\mathrm{H}}$. Using the diagnostic method of Munk (1966), Gordon et al. (2003) calculated a basin-scale averaged $K_{\mathrm{H}}$ of $13.3 \times 10^{-4} \mathrm{~m}^{2} \mathrm{~s}^{-1}$ from deep temperature profiles for the Banda and Seram Seas, while van Aken et al. (1988) calculated a value of $9.0 \times 10^{-4} \mathrm{~m}^{2} \mathrm{~s}^{-1}$ for $K_{\mathrm{H}}$ for the deep Banda Sea system. We calculated values of 15 to $20 \times 10^{-4} \mathrm{~m}^{2} \mathrm{~s}^{-1}$ for $K_{\mathrm{M}}$ and $K_{\mathrm{H}}$ for deep water in the vicinity of the Lifamatola Sill. The somewhat higher simulated values, relative to diagnostic estimates, can be explained by the presence of complicated topography around the sill. We remind the reader that in the main depth of the ocean below the thermocline, vertical mixing is small and a background value of $10^{-5} \mathrm{~m}^{2} \mathrm{~s}^{-1}$ for $K_{\mathrm{M}}$ and $K_{\mathrm{H}}$ is generally accepted. We can also refer to other data. Based on radon profiles and deep silicate distribution, Berger et al. (1988) and van Bennekom (1988), respectively, found mixing coefficients as high as $2 \times 10^{-1} \mathrm{~m}^{2} \mathrm{~s}^{-1}$ in the deep Banda Sea. Other studies support our results of large turbulence energy and coefficients of vertical turbulent mixing around topography. The analysis of the Faeroe Bank Channel overflow shows turbulent mixing coefficients with values of $10^{-3} \mathrm{~m}^{2} \mathrm{~s}^{-1}$ to $10^{-2} \mathrm{~m}^{2} \mathrm{~s}^{-1}$, see, e.g. Saunders (1990), Duncan et al. (2003), Mauritzen et al. (2001). Mauritzen et al. (2001) also found that strong mixing extends downstream at the Faeroe Bank Channel overflow, while mixing is more abrupt over the Denmark Strait overflow. Using the Mellor-Yamada turbulence scheme in an idealized sloping basin, Mellor and Wang (1996) found mixing coefficients between $5 \times 10^{-2} \mathrm{~m}^{2} \mathrm{~s}^{-1}$ and $10^{-1} \mathrm{~m}^{2} \mathrm{~s}^{-1}$ in a layer extending $500 \mathrm{~m}$ off the bottom along sloping topography.

In conclusion, we would like to remind the reader that all calculated characteristics refer to the middle of August. Model forcing was specified such that maximum and minimum transports occur in August and February, respectively. However, the analysis showed only very small seasonal variations of turbulence characteristics in the deep ocean. For 


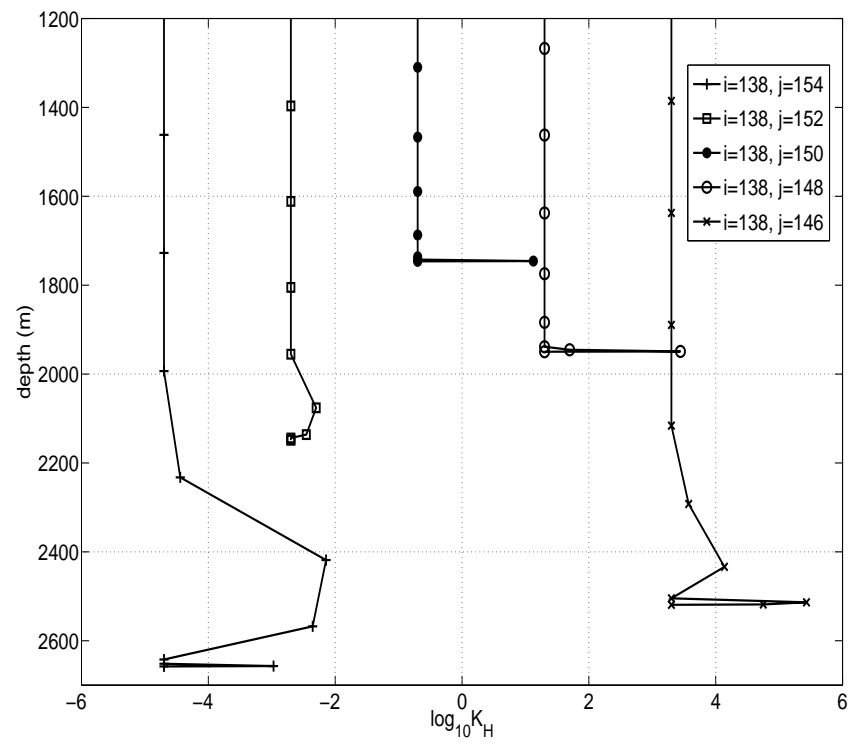

Fig. 14. Profiles of the coefficient of vertical diffusion of temperature and salinity, $K_{\mathrm{H}}\left(\mathrm{m}^{2} \mathrm{~s}^{-1}\right)$. Profiles are offset as in Fig. 8.

illustration, we provide Table 3, where August, February and annual mean values of $\mathrm{q}^{2}$ are presented for the deep layers in the vicinity of the Lifamatola Sill. Thus, August values of turbulence characteristics are quite representative for all months of the year.

\section{Summary and concluding remarks}

The distribution of large-scale turbulence characteristics in the Indonesian seas region on the horizontal scale of order of $100 \mathrm{~km}$, calculated with a regional model, have been investigated. The model is based on the Princeton Ocean Model (POM), incorporating the Mellor-Yamada turbulence closure scheme. We stress that vertical mixing coefficients, $K_{\mathrm{M}}$ (momentum) and $K_{\mathrm{H}}$ (temperature and salinity), were not specified a priori, but calculated within the POM along with twice the turbulence kinetic energy (per unit mass), $q^{2}$, which we have simply called turbulence kinetic energy, master length scale, $\ell$, and the Richardson number, etc. As has been shown in several papers, the incorporation of the Mellor-Yamada closure scheme in the POM gives a reasonable description of turbulence characteristics of the same scale as dynamical characteristics, see, for example Ezer (2000). It is appropriate to stress that the Mellor-Yamada scheme was successfully tested on a wide variety of engineering and geophysical flows (Mellor and Yamada, 1982). By and large, the analysis of POM results has generally been restricted to the distribution of dynamical characteristics. We think the study of consistent turbulence characteristics is also essential to understanding the ocean dynamics.

To avoid confusion, we would like to stress that this paper is not intended to analyze the internal structure of tur- bulence. Our aim was to analyze vertical turbulent mixing in deep layers of the ocean including the bottom boundary layer provided by the Mellor-Yamada scheme of parameterization. The analysis is based essentially on the consideration of the turbulence kinetic energy equation. From the standpoint of this equation, we consider turbulence that is generated by the shear of large-scale ocean currents and by the large-scale wind turbulence. So, our focus is on turbulence associated with basin-scale motions in the Indonesian seas. This is the main reason why we refer to the analyzed turbulence as largescale turbulence. The effect of shear is balanced by the work of buoyancy forces, dissipation of the energy, vertical and horizontal diffusion, and vertical and horizontal advection. The contribution of small-scale motions (e.g. lee waves) into the shaping of $q^{2}$ is not considered explicitly. For example, the lee waves occur at much smaller scales, order of $100 \mathrm{~m}$. The analysis of such motions usually requires a nonhydrostatic model, very detailed bottom topography and horizontal grid spacing on the order of $10 \mathrm{~m}$ (see, e.g. Xing and Davies, 2006 and Xing and Davies, 2007). The effect of internal waves is recognized separately but parameterized in the POM very crudely by the introduction of background mixing. It is worth noting here that currently there are no GCMs that are able to simulate simultaneously large-scale features of the circulation and such motions as small-scale eddies, the filaments coming off eddies, internal waves or lee waves. The study of such motions is extremely important from the standpoint of the internal structure of turbulence, but all known GCMs parameterize such motions. This does not mean that characteristics of turbulence provided by GCMs are of no interest. For example, the simple Munk model based on the 1-D temperature equation is used by many researchers to obtain an estimate of basin-scale turbulence mixing.

The regional model of the Indonesian seas circulation extends throughout the entire Indonesian seas region. There are $250 \times 250$ grid cells in the horizontal with resolution of $\sim 10 \mathrm{~km}$ and $29 \sigma$ levels in the vertical. All major topographic features in the region are resolved. The model has four open ports to simulate the impact of major currents entering and exiting the region; 3 in the Pacific for the Mindanao Current, New Guinea Coastal Current and North Equatorial Counter Current, and 1 in the Indian Ocean through which the ITF exits the model domain. POM recommended boundary conditions are used at closed boundaries. At the surface, heat flux is calculated from surface flux climatology, and wind stress is calculated from monthly climatological winds.

The model allowed us to learn a lot about the distribution of dynamical characteristics (currents, temperature and salinity) in the Indonesian seas. We think that our estimates of large-scale turbulence characteristics are useful as well. In addition to the comparison with diagnostic estimates of mixing coefficients by Gordon et al. (2003), van Aken et al. (1988) and van Aken et al. (1991), our conclusion on adequacy of estimated turbulence characteristics is based also 
Table 3. Near bottom values of $q^{2}$ in August, February and annual mean at 3 points across the Lifamatola Sill. All units in $m^{2} s^{-3}$.

\begin{tabular}{|c|c|c|c|c|c|c|c|c|c|}
\hline & \multicolumn{3}{|c|}{$j=154$} & \multicolumn{3}{|c|}{$j=150$} & \multicolumn{3}{|c|}{$j=146$} \\
\hline & $q_{\text {Aug }}^{2}$ & $q_{\mathrm{Feb}}^{2}$ & $q_{\text {Ann Mean }}^{2}$ & $q_{\mathrm{Aug}}^{2}$ & $q_{\mathrm{Feb}}^{2}$ & $q_{\text {Ann Mean }}^{2}$ & $q_{\text {Aug }}^{2}$ & $q_{\mathrm{Feb}}^{2}$ & $q_{\text {Ann Mean }}^{2}$ \\
\hline$\sigma(k b-6)$ & $2.1 e-5$ & $2.0 \mathrm{e}-5$ & $2.1 e-5$ & $1.1 \mathrm{e}-9$ & $1.1 \mathrm{e}-9$ & $1.1 \mathrm{e}-9$ & $1.1 \mathrm{e}-9$ & $1.1 \mathrm{e}-9$ & $1.1 \mathrm{e}-9$ \\
\hline$\sigma(k b-5)$ & $3.1 \mathrm{e}-5$ & $3.1 \mathrm{e}-5$ & $3.1 \mathrm{e}-5$ & $1.1 \mathrm{e}-9$ & $1.1 \mathrm{e}-9$ & $1.1 \mathrm{e}-9$ & $5.2 \mathrm{e}-5$ & $4.0 \mathrm{e}-5$ & $4.6 e-5$ \\
\hline$\sigma(k b-4)$ & $7.2 \mathrm{e}-5$ & $7.4 e-5$ & $7.3 e-5$ & $1.1 \mathrm{e}-9$ & $1.1 \mathrm{e}-9$ & $1.1 \mathrm{e}-9$ & $1.0 \mathrm{e}-4$ & $6.8 e-5$ & $8.4 \mathrm{e}-5$ \\
\hline$\sigma(k b-3)$ & $1.1 \mathrm{e}-9$ & $1.1 \mathrm{e}-9$ & $1.1 \mathrm{e}-9$ & $1.1 \mathrm{e}-9$ & $1.1 \mathrm{e}-9$ & $1.1 \mathrm{e}-9$ & $1.1 \mathrm{e}-9$ & $1.1 \mathrm{e}-9$ & $1.1 \mathrm{e}-9$ \\
\hline$\sigma(k b-2)$ & $1.1 \mathrm{e}-9$ & $1.1 \mathrm{e}-9$ & $1.1 \mathrm{e}-9$ & $1.1 \mathrm{e}-9$ & $1.1 \mathrm{e}-9$ & $1.1 \mathrm{e}-9$ & $1.3 e-5$ & $1.7 e-5$ & $1.5 e-5$ \\
\hline$\sigma(k b-1)$ & $2.4 \mathrm{e}-5$ & $2.1 \mathrm{e}-5$ & $2.3 e-5$ & $8.2 \mathrm{e}-5$ & $1.0 \mathrm{e}-4$ & $9.1 e-5$ & $5.0 \mathrm{e}-6$ & $7.4 \mathrm{e}-6$ & $6.2 \mathrm{e}-6$ \\
\hline
\end{tabular}

on results of the analysis of their compatibility with some general principles.

We found a consistent distribution of turbulence characteristics on the scale of order of $100 \mathrm{~km}$ for the entire Indonesian seas region. However, the interaction of the large-scale turbulence with shear flow around basic topographic features in the area appears to be of primary interest. The analysis of turbulence characteristics in the vicinty of basic topographic features, such as the North Sangihe Ridge, the Dewakang Sill, the sills surrounding the Halmahera Sea (specifically the north and south sills), and the Lifamatola Sill, revealed very large values of turbulence kinetic energy, $q^{2}$, and coefficients of vertical mixing, $K_{\mathrm{M}}$ and $K_{\mathrm{H}}$, in deep water around these topographic features. $q^{2}$ and mixing coefficients reduce to POM background values in the interior of the ocean away from topographic features and outside the upper mixed layer and the vicinity of strong currents in the thermocline. The turbulence kinetic energy, $q^{2}$, basically determines mixing coefficients, especially in the interior of the ocean where the scale $\ell$ is almost constant. By and large, the structure of turbulence characteristics in these regions turned out to be similar. Because of these results, and since the Lifamatola Strait is very important dynamcially and some estimates of mixing coefficients are available there, we decided to focus our detailed analysis of turbulence characteristics around the Lifamatola Sill.

Model simulated deep water transports across the Lifamatola Sill are in good agreement with those estimated by van Aken et al. (1988) but are somewhat less than those estimated by van Aken et al. (2009). Simulated velocities show a southward flow extending from below $1200 \mathrm{~m}$ to the bottom through the sill. The structure of the simulated velocity profile at the sill is in very good agreement with that observed by van Aken et al. (2009), which shows a southward flow extending from below $1200 \mathrm{~m}$ to the bottom. We argue that the comparison of structures of velocity profiles is more important than that of separate values. Southward velocities increase with depth to a maximum value of over $0.15 \mathrm{~m} \mathrm{~s}^{-1}$ at $\sim 1700 \mathrm{~m}$. Model velocities across the sill are in very good agreement with those of Broecker et al. (1986) but are less than those measured by van Aken et al. (1988) and van Aken et al. (2009). Note that some uncertainty remains in esti- mating deep transport through the Lifamatola Strait. Moving away from the sill and into deeper waters both north and south, these southward currents extend to a depth of almost $2400 \mathrm{~m}$, below which strong simulated current reversals are seen in both the southern Maluku and Seram Seas. A notable rapid change in velocity magnitude near the bottom due to the POM bottom boundary condition is seen in all profiles.

The distribution of $q^{2}$ is quite adequately reproduced by the model. The structure of $q^{2}$ shows that to the north of the Lifamatola Sill (in the Maluku Sea) and to the south of the Sill (in the Seram Sea) large values of $q^{2}$ occur in the deep layer extending several hundred meters above the bottom. Above this layer, $q^{2}$ values are small and are set to the model background value. This increase in $q^{2}$ above the bottom is reasonable because the intensity of turbulence should first increase when one moves downwards and then decrease at the very bottom. The pronounced increase of $q^{2}$ near the very bottom is probably due to the increase of velocity shear and the corresponding shear production of $q^{2}$ very close to the bottom.

Since the turbulence length scale, $\ell$, in the Mellor-Yamada closure scheme is calculated from the solutions to both the $q^{2}$ and $q^{2} \ell$ equations, we estimated all terms in these equations separately to reveal the leading factors. In 4 of the 5 profiles analyzed, a balance exists between shear production of $q^{2}$ and its dissipation close to the bottom due to increased velocity gradient. Notably, there are $\sigma$ levels at which any and all terms can be important; vertical diffusion is important at one $\sigma$ level only, while horizontal diffusion is important at more levels, and the work of buoyancy forces is unimportant at 1 profile only. The same features are seen for the $q^{2} \ell$ profiles.

Shear production values increase as one moves towards the bottom, and decrease above the bottom due to a reduction in shear before increasing rapidly just above the bottom due to increased shear. The work of buoyancy force values decrease gradually as one moves down through the water column. Away from the sill, in deeper water, increased values are seen for a depth of several hundred meters above the bottom, due to an increase in the mixing coefficient, $K_{\mathrm{H}}$, before decreasing again as the bottom is approached. 
For turbulence length scale, $\ell$, constant values are seen in the main depth of the ocean which rapidly decrease close to the bottom, as one would expect. However, in deep profiles away from the sill, the effect of topography results in the structure being unreasonably complicated as one moves towards the bottom. Since it is difficult to find any physical arguments to explain this rapid increase of $\ell$, we doubt that $\ell$ is reproduced near the bottom adequately by the model considered. Nevertheless, this inconsistency does not influence the dynamical characteristics substantially.

Using the diagnostic method of Munk (1966), Gordon et al. (2003) calculated a basin-scale averaged deep water $K_{\mathrm{H}}$ of $13.3 \times 10^{-4} \mathrm{~m}^{2} \mathrm{~s}^{-1}$ from temperature profiles for the Banda and Seram Seas, while van Aken et al. (1988) calculated a value of $9.0 \times 10^{-4} \mathrm{~m}^{2} \mathrm{~s}^{-1}$ for $K_{\mathrm{H}}$ for the deep Banda Sea system. We calculated values of 15 to $20 \times 10^{-4} \mathrm{~m}^{2} \mathrm{~s}^{-1}$ for $K_{\mathrm{M}}$ and $K_{\mathrm{H}}$ for deep water in the vicinity of the Lifamatola Sill. The somewhat higher simulated values can be explained by the presence of steep topography around the sill. We remind the reader that in the main depth of the ocean below the thermocline, vertical mixing is small and a background value of $10^{-5} \mathrm{~m}^{2} \mathrm{~s}^{-1}$ for $K_{\mathrm{M}}$ and $K_{\mathrm{H}}$ is generally accepted. We can also refer to other data that support our results of large coefficients of vertical turbulent mixing around topography. Based on radon profiles and deep silicate distribution, Berger et al. (1988) and van Bennekom (1988), respectively, found mixing coefficients as high as $2 \times 10^{-1} \mathrm{~m}^{2} \mathrm{~s}^{-1}$ in the deep Banda Sea. The analysis of the Faeroe Bank Channel overflow showed turbulence mixing coefficients with values of $10^{-3} \mathrm{~m}^{2} \mathrm{~s}^{-1}$ to $10^{-2} \mathrm{~m}^{2} \mathrm{~s}^{-1}$, see, e.g. Saunders (1990), Duncan et al. (2003) and Mauritzen et al. (2001). Mauritzen et al. (2001) also found that strong mixing extends downstream of the Faeroe Bank Channel overflow, while mixing is more abrupt over the Denmark Strait overflow. In an idealized sloping basin, Mellor and Wang (1996) found mixing coefficients between $5 \times 10^{-2} \mathrm{~m}^{2} \mathrm{~s}^{-1}$ and $10^{-1} \mathrm{~m}^{2} \mathrm{~s}^{-1}$ along sloping topography in a layer extending $500 \mathrm{~m}$ off the bottom.

Acknowledgements. K. O'Driscoll would like to thank the Naval Oceanographic Office for supporting his graduate education. V. Kamenkovich gratefully acknowledges support from the National Science Foundation through grants OCE 96-33470 and OCE 01-18200.

Edited by: A. Schiller

\section{References}

Alford, M., Gregg, M., and Ilyas, M.: Diapycnal mixing in the Banda Sea: results of the first microstructure measurements in the Indonesian throughflow, Geophys. Res. Lett., 26, 2741-2744, 1999.
Berger, G., Bennekom, A. V., and Kloosterhuis, H.: Radon profiles in theIndonesian archipelago, Neth. J. Sea Res., 22, 395-402, 1988.

Broecker, W. S., Patzert, W. C., Toggweiler, J. R., and Stuiver, M.: Hydrography, chemistry, and radioisotopes in the southeast Asian waters, J. Geophys. Res., 91, 14345-14354, 1986.

Burchard, H.: On the $q^{2} \ell$ Equation by Mellor and Yamada (1982), J. Phys. Oceanogr., 31, 1377-1387, 2001.

Conkright, M. E., Locarnini, R. A., Garcia, H. E., O’Brien, T. D., Boyer, T. P., Stephens, C., and Antonov, J.: World Ocean Atlas 2001: Objective Analyses, Data Statistics, and Figures, Cdrom documentation, National Oceanographic Data Center, Silver Spring, MD, 2002.

Cummins, P.: Stratified flow over topography: time-dependent comparisons between model solutions and observations, Dynam. Atmos. Oceans, 33, 43-72, 2000.

da Silva, A. M., Young, C. C., and Levitus, S.: Atlas of Surface Marine Data 1994, Volume 2: Anomalies of Directly Observed Quantities, NOAA Atlas NESDIS 7, US Department of Commerce, NOAA, NESDIS, 1994.

Duncan, L., Bryden, H. L., and Cunningham, S. A.: Friction and mixing in the Faroe Bank Channel outflow, Oceanol. Acta, 26, 473-486, 2003.

Ezer, T.: On the seasonal mixed layer simulated by a basin-scale ocean model and the Mellor-Yamada turbulence scheme, J. Geophys. Res., 105, 16843-16855, 2000.

Ezer, T.: Entrainment, diapycnal mixing and transport in threedimensional bottom gravity current simulations using the MellorYamada turbulence scheme, Oc. Mod., 9, 151-168, 2005.

Ezer, T. and Mellor, G.: A generalized coordinate ocean model and a comparison of the bottom boundary layer dynamics in terrainfollowing and z-level grids, Oc. Mod., 6, 379-403, 2004.

Ezer, T. and Weatherly, G. L.: A numerical study of the interaction between a deep cold jet and the bottom boundary layer of the ocean, J. Phys. Oceanogr., 20, 801-816, 1990.

Fieux, M., Andrie, C., Delecluse, P., Ilahude, A. G., Kartavtseff, A., Mantisi, F., Molcard, R., and Swallow, J. C.: Measurements within the Pacific-Indian oceans throughflow region, Deep-Sea Res. I, 41, 1091-1130, 1994.

Gordon, A. L.: Oceanography of the Indonesian Seas and Their Throughflow, Oceanography, 18, 14-27, 2005.

Gordon, A. L., Giulivi, C. F., and Ilahude, A. G.: Deep topographic barriers within the Indonesian seas, Deep-Sea Res. II, 50, 22052228, 2003.

Grist, J. P. and Josey, S. A.: Inverse analysis adjustment of the SOC air-sea flux climatology using ocean heat transport constraints, J. Climate, 20, 3274-3295, 2003.

Kamenkovich, V. M., O’Driscoll, K. T. A., and Nechaev, D.: Dynamics of the Indonesian Seas. Part II - The role of pressure head, J. Mar. Res., 67, 159-184, 2009.

Marchesiello, P., McWilliams, J. M., and Shchepetkin, A.: Open boundary conditions for log-term integration of regional oceanic models, Oc. Mod., 3, 1-20, 2001.

Mauritzen, C., Price, J., Sanford, T., and Torres, D.: Circulation and mixing in the Faeroese Channels, Deep-Sea Res. II, 52, 883-913, 2001.

Mellor, G. L.: Users Giude for a three-dimensional, primitive equation, numerical ocean model, Tech. rep., Program in Atmospheric and Oceanic Sciences, Princeton University, 2004. 
Mellor, G. L. and Wang, X.: Pressure Compensation and the Bottom Boundary Layer, J. Phys. Oceanogr., 26, 2214-2222, 1996.

Mellor, G. L. and Yamada, T.: Development of a turbulence closure model for geophysical fluid problems, Rev. Geophys. Space Phys., 20, 851-875, 1982.

Munk, W. H.: Abyssal Recipes, Deep-Sea Res., 13, 707-730, 1966.

O'Driscoll, K. T. A.: A regional model of the Indonesian Seas circulation, Phd dissertation, Department of Marine Science, The University of Southern Mississippi, 2007.

O’Driscoll, K. T. A. and Kamenkovich, V. M.: Dynamics of the Indonesian seas circulation. Part I - The influence of bottom topography on temperature and salinity distributions, J. Mar. Res., 67, 119-157, 2009.

Oey, L. Y., Mellor, G. L., and Hires, R. I.: A three-dimensional simulation of the Hudson-Raritan estuary. Part I: Description of the model and model simulations, J. Phys. Oceanogr., 15, 1676$1692,1985$.

Polzin, K. L., Speer, K. G., Toole, J. M., and Schmitt, R. W.: Intense mixing of Antarctic Bottom Water in the equatorial Atlantic Ocean, Nature, 380, 54-57, 1996.

Rosenfield, D., Kamenkovich, V., O'Driscoll, K., and Sprintall, J.: Validation of a regional Indonesian seas model based on a comparison between model and INSTANT transports, Dyns. Atm. Oc., 50, 313-330, 2010.

Saunders, P.: Cold outflow from the Faeroe Bank Channel, J. Phys. Oceanogr., 20, 29-43, 1990.

Schiller, A., Godfrey, J. S., McIntosh, P. C., Meyers, G., and Wijffels, S. E.: Seasonal Near-Surface Dynamics and Thermodynamics of the Indian ocean and Indonesian Throughflow in a Global Ocean General Circulation Model, J. Phys. Oceanogr., 28, 22882312, 1998.

Sprintall, J., Gordon, A., Molcard, R., Ilahude, G., Bray, N., Chereskin, T., Cresswell, G., Feng, M., Ffield, A., Fieux, M., Hautala, S., Luick, J., Meyers, G., Potemra, J., Susanto, D., and Wijffels, S.: The Indonesian Throughflow: Past, Present and Future Monitoring. Proceedings from the Sustained Observations for Climate of the Indian Ocean Workshop, Perth, Australia, Technical report, IOC/CLIVAR, 2000.
Sprintall, J., Wijffels, S., Gordon, A. L., Ffield, A., Molcard, R., Susanto, R. D., Soesilo, I., Sopaheluwakan, J., Surachman, Y., and van Aken, H.: INSTANT: A new international array to measure the Indonesian Throughflow, Eos, 85, 369-376, 2004.

Stommel, H. and Fedorov, K. N.: Small scale structure in temperature and salinity near Timor and Mindanao, Tellus, 19, 306-324, 1967.

van Aken, H. M., Punjanan, J., and Saimima, S.: Physical aspects of the flushing of the East Indonesian basins, Neth. J. Sea Res., 22, 315-339, 1988.

van Aken, H. M., Bennekom, A. J. V., Mook, W. G., and Postma, H.: Application of Munk's abyssal recipes to tracer distributions in the deep waters of the southern Banda basin, Oceanologica Acta, 14, 151-162, 1991.

van Aken, H. M., Brodjonegoro, I. S., and Jaya, I.: The deep-water motion through the Lifamatola Passage and its contribution to the Indonesian throughflow, Deep-Sea Res. I, 56, 1203-1216, 2009.

van Bennekom, A.: Deep-water transit times in the eastern Indonesian basins, calculated from dissolved silica in deep and interstitial waters, Neth.J. Sea Res., 22, 341-354, 1988.

Wijesekera, H. W., Allen, J. S., and Newberger, P. A.: Modeling study of turbulent mixing over the continental shelf: comparison of turbulent closure schemes, J. Geophys. Res., 108, 1-25, doi:10.1029/2001JC001234, 2003.

Xing, J. and Davies, A. M.: Influence of stratification and topography upon internal wave spectra in the region of sills, Geophys. Res. Lett., 33, 1-5, doi:10.1029/2006GL028092, 2006.

Xing, J. and Davies, A. M.: On the importance of non-hydrostatic processes in determining tidally induced mixing in sill regions, Cont. Shelf Res., 27, 2162-2185, 2007. 